\title{
Quantitative Spectral Radiance Measurements in the HYMETS Arc Jet
}

\author{
Paul M. Danehy, ${ }^{1}$ Drew V. Hires, ${ }^{2}$ Craig T. Johansen, ${ }^{3}$ Brett F. Bathel, ${ }^{4}$ Stephen B. Jones, ${ }^{5}$ Jeffrey G. Gragg, ${ }^{6}$ \\ and Scott C. Splinter ${ }^{7}$ \\ NASA Langley Research Center, Hampton VA, 23681-2199
}

\begin{abstract}
Calibrated spectral radiance measurements of gaseous emission spectra have been obtained from the HYMETS (Hypersonic Materials Environmental Test System) $400 \mathrm{~kW}$ arc-heated wind tunnel at NASA Langley Research Center. A fiber-optic coupled spectrometer collected natural luminosity from the flow. Spectral radiance measurements are reported between 340 and 1000 nm. Both Silicon Carbide (SiC) and Phenolic Impregnated Carbon Ablator (PICA) samples were placed in the flow. Test gases studied included a mostly- $\mathrm{N}_{2}$ atmosphere (95\% nitrogen, 5\% argon), a simulated Earth Air atmosphere (75\% nitrogen, $20 \%$ oxygen, $5 \%$ argon) and a simulated Martian atmosphere (71\% carbon dioxide, $24 \%$ nitrogen, $5 \%$ argon). The bulk enthalpy of the flow was varied as was the location of the measurement. For the intermediate flow enthalpy tested (20 $\mathrm{MJ} / \mathrm{kg}$ ), emission from the Mars simulant gas was about 10 times higher than the Air flow and 15 times higher than the mostly- $\mathrm{N}_{2}$ atmosphere. Shock standoff distances were estimated from the spectral radiance measurements. Within-run, run-to-run and day-to-day repeatability of the emission were studied, with significant variations (15-100\%) noted.
\end{abstract}

\section{Introduction}

A rcjet facilities allow ground-based testing and characterization of new materials intended for hypersonic vehicles, including those designed for planetary entry. The Hypersonic Material Environmental Test System (HYMETS) at NASA Langley is a small-scale arcjet facility which is suitable for developing measurement techniques and screening new materials. HYMETS has instrumentation to measure stagnation pressure; heat flux (semi-catalytic hot-wall, fully-catalytic cold-wall, and/or non-catalytic cold-wall); gas mass flow rates; sonic, stagnation, and bulk specific enthalpy; and arc current, voltage, and power. ${ }^{1}$ Nonintrusive measurements of additional flow parameters are being developed. Nitric oxide (NO) planar laser-induced fluorescence (PLIF) has recently been used in the HYMETS arcjet to measure axial and radial velocities as well as to visualize the flow. ${ }^{2}$ Several nonintrusive measurement techniques have been applied by others to arcjet flows. Diode laser absorption has been demonstrated for making simultaneous velocity and temperature measurements of an argon arcjet plume. ${ }^{3}$ Oxygen (O)-atom and nitrogen (N)-atom laser-induced fluorescence (LIF) have been used to provide temperature, velocity and species concentration (number density) measurements at a single point or along a line ${ }^{4,5,6}$ NO LIF and $\mathrm{O}$-atom LIF have previously been used in arcjets to measure translational temperatures of $\mathrm{O}$ and rotational temperatures of $\mathrm{NO}^{7,8}$ Fluorescence-based methods typically have spatial resolution on the order of $1 \mathrm{~mm}$ because the measurement is made at the intersection of an incident laser beam and an orthogonal viewing direction. References 9 and 10 give additional descriptions of techniques that have been used to make nonintrusive measurements in arcjets.

${ }^{1}$ Research Scientist, Advanced Sensing and Optical Measurement Branch, MS 493, AIAA Associate Fellow.

${ }^{2}$ NASA LARSS undergraduate student, University of Connecticut.

${ }^{3}$ Post-Doctoral Researcher, National Institute of Aerospace, Hampton Virginia; Currently Asst. Prof, University of Calgary, Calgary, Canada.

${ }^{4}$ Graduate Student, University of Virginia and NASA Graduate Co-op, AIAA Student Member.

${ }^{5}$ Research Technician, Advanced Sensing and Optical Measurement Branch, MS 493.

${ }^{6}$ Research Technician, Structures Experiments Branch, MS 188D.

${ }^{7}$ Aerospace Engineer, Structural Mechanics and Concepts Branch, MS 190, AIAA Member. 
The most commonly applied optical instrumentation in arcjets has been emission spectroscopy (see Refs. 11-13 and references therein). Emission spectroscopy is generally easier to perform and cheaper than laser based techniques. Emission spectroscopy can probe any species that naturally emits light at high-temperature conditions. One drawback of this method is that only excited states are detected, so simultaneous temperature measurements and the assumption of equilibrium are often required to determine atomic or molecular concentrations. Another significant drawback of emission spectroscopy is that measurements are path-averaged. That is, they lack spatial resolution along the line of sight of the measurement. Thus, to infer spatial information from the spectra, additional assumptions and/or processing is needed, such as tomographic reconstruction. The most commonly used tomographic inversion method in plasmas and arcjets is the Abel inversion, which assumes radial symmetry. ${ }^{14}$ This method requires measurements at different (often parallel) rays lying in a plane perpendicular to the axis of symmetry of an arcjet flow. Such measurements can be inverted to produce radial spectral and parameter (temperature, concentration) profiles. In the present experiment, Abel inversion has not been performed. Instead, we report path-averaged measurements in the shock layer of a sample being tested in an arcjet. Figure 1 shows the optical arrangement near the sample. Flow is left to right, causing a bow shock wave to form in front of the end-on cylindrical sample. The pathaveraged measurements are made parallel to the model surface, perpendicular to and passing through the centerline axis of the facility. The streamwise distance $(d)$ from the sample is varied in the $\mathrm{x}$-direction. These measurements show how the gas emission changes from the freestream, passing through the shock wave, and then nearing the sample. The enthalpy of the flow is also varied during the experiment to show how, at one spatial location, the radiation varies with enthalpy. Three different test gases were used: a mostly- $\mathrm{N}_{2}$ flow, an Earth Air-simulant and a Martian atmosphere simulant. Finally, the type of sample tested was varied: both silicon carbide (SiC) disks and Phenolic Impregnated Carbon Ablator (PICA) were studied. PICA tests were performed only in Earth-Air simulant.

Emission spectroscopy measurements obtained in arcjets are useful for three reasons: 1) they offer qualitative insight into the species present in the environment which contribute to the ablating or degrading of hypersonic materials, including species being released by the materials themselves, 2) they can provide qualitative and quantitative information about the operating conditions produced by the arcjet facility and 3) the measured quantitative spectral radiance can be directly compared with computations of the flow, to validate or verify numerical prediction of the flowfield and to evaluate or validate radiation models in those codes. Since radiation is an important component of the heat transfer to the surface of entry vehicles, it is important to validate such predictive capabilities. A recent theoretical NASA study of radiative heating uncertainty for a Mars-return Earth entry showed an overall uncertainty of about $\pm 80 \%$ in the radiative heat transfer. ${ }^{15}$ For this mission type, radiative heating was the dominant source of heating at the stagnation point, for entry velocities higher than $11.5 \mathrm{~km} / \mathrm{s}$, assuming a 1 meter radius sphere. At $15 \mathrm{~km} / \mathrm{s}$, radiative heating was estimated to be higher than convective heating by a factor of approximately 3 or 16, depending on whether the heat shield is assumed to be non-ablating or ablating, respectively. ${ }^{15}$ The report shows that radiation is increasingly important for larger nose-radius entry vehicles as would be required to return humans from Mars.

\section{Experimental Methods}

\section{A. HYMETS Arcjet Facility}

Tests were conducted at NASA Langley Research Center in the HYMETS facility, which is an arc-jet plasma wind tunnel powered by a $400 \mathrm{~kW}$ supply. A schematic of the flow facility is shown in Fig. 2. When compared to other, larger arc-heated wind tunnel facilities, significant advantages of HYMETS include the relatively small workforce required to operate the facility (typically one technician), long run times (up to several hours), short down-time between runs and sample changes (less than one hour), and relatively low operating costs. Also, seven optical ports, several of which can be seen in Fig. 2, offer a variety of views of the flow and test specimens. The 
access ports can be fitted with a $63.5 \mathrm{~mm}$ ( $2.75 \mathrm{inch})$ diameter UV-grade fused silica (quartz) window to provide optical access at wavelengths down into the vacuum ultraviolet.

A segmented-constrictor direct-current electric arc-heater serves as an arc plasma generator. The slightly diverging flow issues from a convergent-divergent 8 degree half-angle Mach 5 conical copper nozzle with a 12.7 $\mathrm{mm}\left(0.5\right.$ inch) diameter throat and a $63.5 \mathrm{~mm}\left(2.5\right.$ inch) diameter exit. Process gasses consist of nitrogen $\left(\mathrm{N}_{2}\right)$, oxygen $\left(\mathrm{O}_{2}\right)$, carbon dioxide $\left(\mathrm{CO}_{2}\right)$, and argon $(\mathrm{Ar})$. Test gasses are injected tangentially into the bore of the arc plasma generator at six discrete locations, where they are heated by a high-voltage electric-arc maintained between the cathode and anode to create a high-temperature ionized plasma flow. The electric-arc is spin-stabilized in the arc plasma generator by the vortex motion of the injected test gasses. The test gasses used in the arc plasma generator are supplied by several compressed gas cylinders and can be custom mixed to any desired atmosphere. Adjustable volume percentages of $\mathrm{N}_{2}$ and $\mathrm{Ar}$ are used as shield gasses near the cathode and anode, respectively, to protect the electrodes from rapid oxidation.

The plasma flow from the arc plasma generator is accelerated through the nozzle and exhausted into a $0.6 \mathrm{~m} \mathrm{(2}$ $\mathrm{ft})$ diameter by $0.9 \mathrm{~m}$ (3 ft) long vacuum test chamber where it stagnates on one of four water-cooled specimen/instrumentation injection stings arranged symmetrically around the inside circumference of the test chamber. The flow is then captured by a collector cone with a $0.2 \mathrm{~m}$ ( 8 inch) diameter inlet plane, a $0.15 \mathrm{~m}(6 \mathrm{inch})$ diameter constant cross-section diffuser, and a coiled-copper tubing heat exchanger to decelerate and cool the flow. A two-stage, continuous-flow, high-mass-capacity, mechanical pumping system, is used to evacuate the plasma flow from the facility. The whole facility is cooled by a re-circulating chiller with associated booster pumps and heat exchangers.

Four probes can alternately be hydraulically injected into the flow approximately $51 \mathrm{~mm}$ ( 2 inches) downstream of the nozzle exit. Three of these probes typically consist of a pitot tube to measure stagnation pressure, a Gardon gauge and a copper slug calorimeter to measure fully-catalytic cold-wall heat flux. The fourth probe is usually configured as either a Teflon ${ }^{\circledR}$ slug calorimeter to measure non-catalytic cold-wall heat flux, a silicon carbide (SiC) probe to measure semi-catalytic hot-wall heat flux, or a test specimen. For the results presented herein in which a probe was inserted into the flow, the probe contained either a SiC or PICA sample. The $\mathrm{SiC}$ specimen consisted of a $25.4 \mathrm{~mm}$ diameter $\mathrm{x} 3.2 \mathrm{~mm}$ thick solid $\mathrm{SiC}$ disk held in place by a cylindrical $\mathrm{SiC}$ specimen holder that had a 33 $\mathrm{mm}$ outside diameter. The corners of the holder are rounded with a radius of $3.2 \mathrm{~mm}$. The $\mathrm{SiC}$ disk was recessed slightly $(0.75 \mathrm{~mm})$ from the front of the specimen holder. Consequently, when the distance of the measurement volume in front of the sample, $d$, equals zero, the center of the measurement volume is actually $0.75 \mathrm{~mm}$ in front of the $\mathrm{SiC}$ disk, though the center of the measurement volume is just clipping the specimen holder. For further details of the $\mathrm{SiC}$ specimen, its holder and the sting assembly, including photographs of the setup, see Ref. 1. The cylindrical PICA sample had a $33 \mathrm{~mm}$ diameter and was $15 \mathrm{~mm}$ thick. The outer $9.4 \mathrm{~mm}$ of this thickness was exposed to the flow, while the remaining material was held in a $33 \mathrm{~mm}$ diameter, $12.5 \mathrm{~mm}$ long $\mathrm{SiC}$ sample holder. The outer edge of this cylindrical PICA sample had a sharp edge, though this quickly ablated away when the sample was inserted into the flow. The SiC and PICA specimens protruded into the flow the same distance from the sting (within $0.5 \mathrm{~mm}$ ).

A more thorough description of the facility, including detailed explanations of the gas injection system, the instrumentation available in the facility, schematics and photographs, comparisons with other similar facilities, and measured free stream quantities across a wide range of flow conditions can be found in Ref. 1 . 


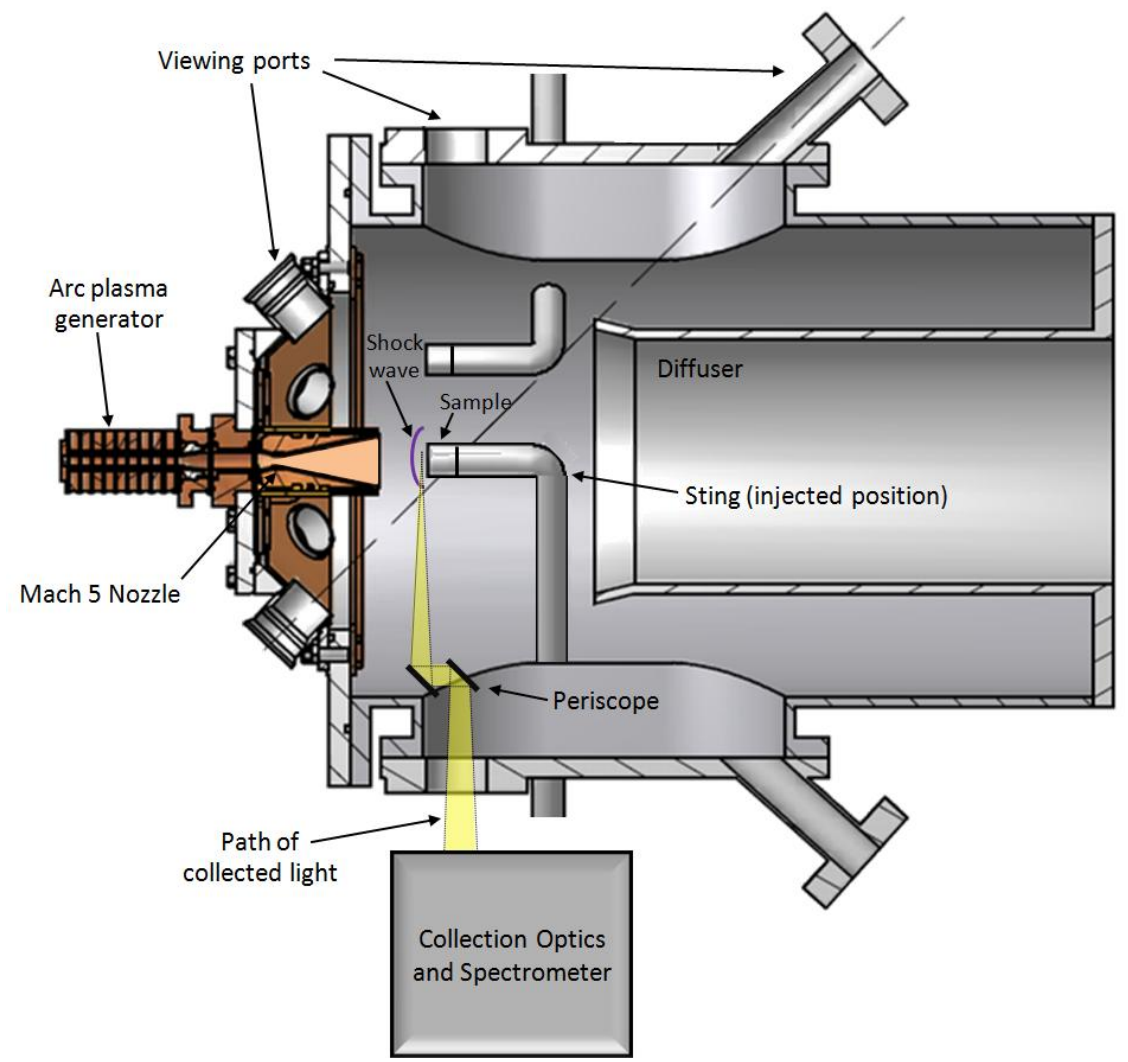

Figure 2. HYMETS Facility, with arc plasma generator on left, L-shaped sample holders in middle, and diffuser/collector on right. Flow is from left to right. The yellow area indicates the path of collect emission from the front of the sample.

Table 1. Nominal test gas compositions, by mass, in percent

\begin{tabular}{cccccc}
\hline \hline Test gas & Abbreviated Name & $\mathrm{N}_{2}$ & $\mathrm{O}_{2}$ & $\mathrm{Ar}$ & $\mathrm{CO}_{2}$ \\
\hline Mostly $\mathrm{N}_{2}$ & $\mathrm{~N}_{2}$ & 95 & - & 5 & - \\
Earth Air Simulant & Air & 75 & 20 & 5 & - \\
Mars Simulant & Mars & 24 & - & 5 & 71 \\
\hline \hline
\end{tabular}

\section{B. Test Conditions}

Three different gas mixtures were used for the present study. These are summarized in Table 1. They are used to simulate atmospheric entry conditions on Mars and Earth. A mostly- $\mathrm{N}_{2}$ mixture is also used to isolate the effects of oxygen chemistry and spectroscopy. The abbreviated names for the gas mixtures shown in the table are used throughout the paper in the text and figures. In all cases, 5\% Ar is used to shield the electrode. The Mars simulant does not have the $97 \% \mathrm{CO}_{2} / 3 \% \mathrm{~N}_{2}$ mixture ratio characteristic of the actual Martian atmosphere because the arcjet electrode oxidize faster, reducing their life, while operating on such a high fraction of $\mathrm{CO}_{2}$. The test conditions are summarized in Table 2. The arc current was varied between 100 and 403 A while the mass flow rate also varied, but over a relatively smaller range. The test matrix has several repeated points. The most commonly repeated points are at the middle current $(150 \mathrm{~A})$, and a measurement volume position of $d=2.2 \mathrm{~mm}$. Most comparisons in the paper are made at this condition and location. Run 12 was a repeat of Runs 4, 6, and 7 and is not shown in detail in the table. Uncertainties in the parameters listed in Table 2 are shown as single values for simplicity though they depend on the conditions, as computed according to Ref. 16. During the experiments, the test section pressure was usually about 1 Torr, although this varies slightly ( $0.6-1.6$ Torr) depending on conditions. This and additional details on the test conditions and uncertainties can be provided by the authors upon request. 
Table 2. Test matrix showing selected runs in the HYMETS arcjet facility. All tests were performed in 2011. Data shown in black were obtained during the run; data in blue were estimated from similar runs at the same nominal conditions. The third row in the table contains the measurement uncertainty.

\begin{tabular}{|c|c|c|c|c|c|c|c|c|c|c|c|}
\hline Date & Run \# & Sample & Test Gas & $\begin{array}{l}\text { Position } \\
(\mathrm{d}, \mathrm{mm})\end{array}$ & $\begin{array}{c}\text { Arc Current } \\
\text { (Amps) }\end{array}$ & $\begin{array}{c}\mathbf{P}_{\text {arc }} \\
(\mathbf{k P a})\end{array}$ & $\begin{array}{c}\text { Mass Flow } \\
\text { (g/sec) }\end{array}$ & $\begin{array}{c}\mathbf{H}_{\text {bulk }} \\
(\mathrm{MJ} / \mathrm{kg})\end{array}$ & $\begin{array}{c}\mathbf{P}_{\text {stagnation }} \\
(\mathbf{k P a})\end{array}$ & $\begin{array}{l}\text { Pyrometer } \\
\text { (degrees C) }\end{array}$ & $\begin{array}{c}\text { Heating Rate } \\
\left(\mathrm{W} / \mathrm{cm}^{2}\right)\end{array}$ \\
\hline (Uncertainty) & - & - & - & $(0.3)$ & (10) & $(0.3)$ & $(0.08)$ & (3) & $(0.05)$ & (15) & $(+/-10 \%)$ \\
\hline 19-Apr & 3 & $\mathrm{SiC}$ & Air & Several Fixed & 152 & 41.6 & 2.26 & 20 & 2.5 & 1440 & 154 \\
\hline \multirow[t]{5}{*}{ 19-Apr } & 4 & $\mathrm{SiC}$ & Air & 2.2 & 102 & 37.6 & 2.26 & 15 & 2.2 & - & 102 \\
\hline & & & & 2.2 & 127 & 39.6 & 2.26 & 18 & 2.36 & 1340 & 127 \\
\hline & & & & 2.2 & 152 & 41.3 & 2.26 & 21 & 2.53 & 1400 & 152 \\
\hline & & & & 2.2 & 176 & 42.8 & 2.26 & 24 & 2.67 & 1520 & 177 \\
\hline & & & & 2.2 & 200 & 43.6 & 2.26 & 28 & 2.75 & 1610 & 210 \\
\hline 20-Apr & 5 & $\mathrm{SiC}$ & $\mathrm{N}_{2}$ & Several Fixed & 152 & 39.9 & 2.29 & 20 & 2.39 & 1670 & 172 \\
\hline \multirow[t]{5}{*}{ 20-Apr } & 6 & $\mathrm{SiC}$ & $\mathrm{N}_{2}$ & 0.7 & 102 & 35.2 & 2.29 & 14 & 1.93 & 1430 & 120 \\
\hline & & & & 0.7 & 127 & 37.9 & 2.29 & 17 & 2.2 & 1570 & 146 \\
\hline & & & & 0.7 & 152 & 40.0 & 2.29 & 20 & 2.4 & 1650 & 172 \\
\hline & & & & 0.7 & 176 & 42.0 & 2.29 & 23 & 2.59 & 1750 & 198 \\
\hline & & & & 0.7 & 201 & 43.7 & 2.29 & 26 & 2.76 & 1830 & 221 \\
\hline 20-Apr & $7 \mathrm{a}$ & $\mathrm{SiC}$ & Mars & Several Fixed & 152 & 37.5 & 2.21 & 22 & 2 & 1510 & 135 \\
\hline \multirow[t]{5}{*}{ 20-Apr } & $7 b$ & $\mathrm{SiC}$ & Mars & 2.2 & 102 & 32.9 & 2.21 & 14 & 1.57 & 1280 & 68 \\
\hline & & & & 2.2 & 127 & 35.6 & 2.21 & 17 & 1.82 & 1390 & 96 \\
\hline & & & & 2.2 & 152 & 37.7 & 2.21 & 21 & 2.02 & 1510 & 134 \\
\hline & & & & 2.2 & 176 & 39.7 & 2.21 & 24 & 2.23 & 1610 & 153 \\
\hline & & & & 2.2 & 201 & 41.6 & 2.21 & 26 & 2.46 & 1700 & 181 \\
\hline 20-Apr & 10 & $\mathrm{SiC}$ & Air & Several Fixed & 152 & 41.6 & 2.27 & 20 & 2.55 & 1390 & 178 \\
\hline 21-Apr & 12 & $\mathrm{SiC}$ & Air/ $/ \mathrm{N}_{2} /$ Mars & 2.2 & $101-200$ & $34.7-112$ & $2.2-8.8$ & 6-28 & $1.6-5.3$ & $1260-1730$ & - \\
\hline 24-Jun & 5 & PICA & Air & Cont. Sweep & 403 & 61.7 & 2.9 & 45 & 3.70 & 2360 & 380 \\
\hline 24-Jun & 6 & PICA & Air & Cont. Sweep & 403 & 62.0 & 2.9 & 45 & 3.70 & 2350 & 377 \\
\hline
\end{tabular}

\section{Emission Spectrometer and Calibration}

An Ocean Optics USB2000 fiber-optic coupled spectrometer was used in the experiment. As shown in Fig. 2, light from the flow was directed into the spectrometer system. Two different spectral detection setups were used, illustrated in Figs. 3(a) and (b).

The first setup used for all the $\mathrm{SiC}$ runs is shown in Fig.3(a). In this configuration, a $609 \mathrm{~mm}$ focal length mirror was located about $1.3 \mathrm{~m}$ from the flow centerline. The magnification of the optical system was measured to be 1.65 , so the $0.6 \mathrm{~mm}$ diameter fiber would, in principle, result in a $0.99 \mathrm{~mm}$ diameter measurement volume at the test sample. However, significant astigmatism caused by using the mirror off axis caused the measurement volume to be significantly larger with two foci, one horizontal and one vertical. To reduce the astigmatism, a variable aperture set to a diameter of $3.0 \pm 0.5 \mathrm{~mm}$ was placed $25 \mathrm{~mm}$ in front of the optical fiber, which reduced the acceptance angle of the fiber, thereby reducing the area of the mirror used. The reduction in signal intensity caused by using the aperture did not adversely affect the ability to make high signal-to-noise ratio measurements during testing. However, calibrations had to be performed with the same aperture diameter as used in the experiments. By using an aperture, a $1.5 \pm 0.2 \mathrm{~mm}$ diameter probe volume was achieved. This probe volume was determined by attaching the fiber to a combination Deuterium/Tungsten lamp with broad spectral output and projecting the emitted light into the test chamber. As shown in Fig. 2, a periscope was used so that the view of the spectrometer could pass along and parallel to the end of the cylindrical test sample. As shown in Fig. 3(a), the optical fiber was mounted on a translation stage oriented in the horizontal plane, so that the movement of the fiber would translate the measurement volume normal to the surface of the test sample (x-direction in Fig. 1). During the facility runs, the fiber was translated to probe different measurement locations. A second stepper motor was used to translate the measurement volume in the spanwise (y) or vertical (z) direction during initial alignment. For the data reported herein, the measurement volume was centered on the flow centerline for all measurements; only the x-location was varied.

Several changes were made to the system prior to testing the PICA samples to improve the magnification, reduce the astigmatism and to increase the range of measurements. The resulting setup is shown in Fig. 3(b). The concave mirror was moved about $0.25 \mathrm{~m}$ closer to the test section and the fiber was moved further away from the mirror to bring the magnification of the optical system closer to 1:1. A magnification of 1.14 was achieved, resulting in an ideal probe volume diameter of $0.69 \mathrm{~mm}$. To reduce the astigmatism, an even smaller aperture $(0.8 \pm 0.2 \mathrm{~mm})$ was used. Also, using the edge of the concave mirror brought the focal point of the optical system closer to an on-axis 
optical system, thereby further reducing astigmatism. For the tests involving PICA, the flow enthalpy was much higher than for $\mathrm{SiC}$ tests. Consequently, the emission was much brighter and the reduction in aperture did not provide enough attenuation to prevent saturation of the camera. The exposure duration could be varied from 10s of seconds to the minimum value of $3 \mathrm{~ms}$ to keep the signal in the middle of the dynamic range of the detector. However, even using the shortest exposure and a small aperture, the signal still saturated the detector. So, UVtransmitting neutral density filters having an optical density of 1.3 were used to further attenuate the emission. After making these changes, the resulting measurement volume diameter was determined experimentally to be $0.9 \pm 0.1$ $\mathrm{mm}$.

(a)

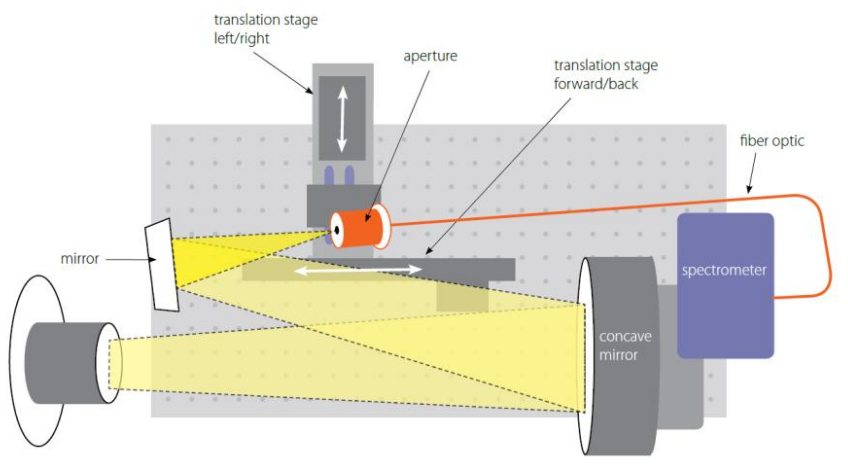

(b)

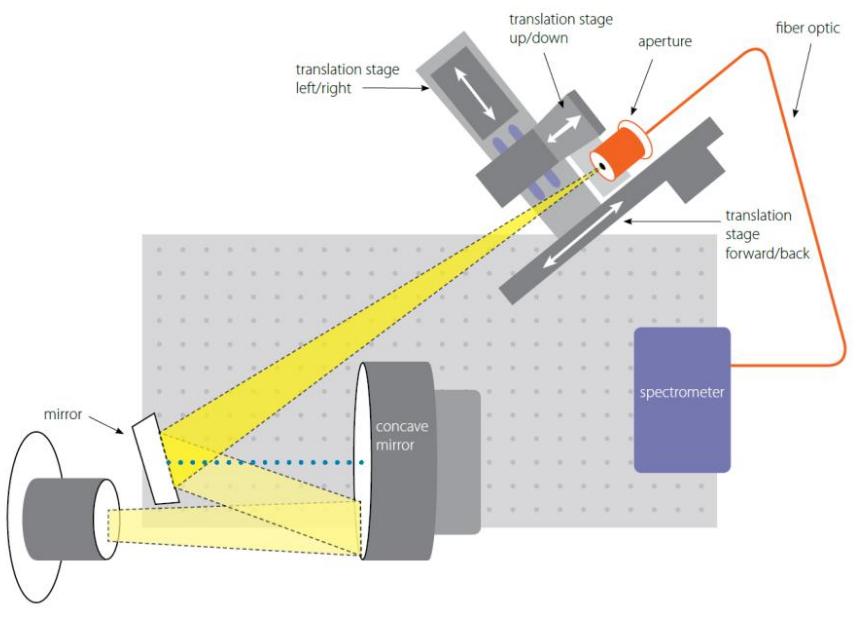

Figure 3. Two different collection optics and spectrometer configurations used in the experiment, (a) used for $\mathrm{SiC}$ runs and (b) used for PICA runs. Note 90 degree counter clockwise rotation of optical setup compared to Fig. 2. The optical breadboard shown is 12 inches wide by 24 inches long. The viewing point is in the bottom left hand corner of each figure. The drawings are roughly to scale.

The spectral response of the optical system was calibrated using a Labsphere calibration lamp, which has a NIST-traceable, calibrated spectral radiance output. The lamp was placed in the test section prior to, and after the runs to provide calibration data. When ND filters were put in place in the optical system, or when the aperture was adjusted, the system was re-calibrated. The calibration lamp has a known spectral output that can be used to determine the absolute spectral response (ASR) of the optical system. When the ASR of this optical system was computed, there was an unexpectedly large ASR for wavelengths less than $330 \mathrm{~nm}$. We believe this was caused by intense visible light collected during the calibration spilling over onto the UV region of the spectrometer, which had very low signal levels. The calibration lamp was tungsten based and had low output in the UV. Using a calibrated Deuterium lamp, which has higher UV and lower visible output, would have allowed us to extend the calibration towards the UV. Because of this anomalous ASR below $330 \mathrm{~nm}$, only data greater than $340 \mathrm{~nm}$ and less than 1000 $\mathrm{nm}$ are reported herein.

The uncertainty in the measured spectral radiance depends on several factors. The first relates to the Labsphere calibration lamp which was calibrated by the manufacturer. There is a transfer uncertainty of the manufacturer's secondary standards relative to the National Institute of Standards and Technology (NIST). For wavelengths between $400 \mathrm{~nm}$ and $1000 \mathrm{~nm}$, this is estimated by the manufacturer to be less than about $1 \%$. Below $400 \mathrm{~nm}$, the 
uncertainty grows with decreasing wavelength to about $4 \%$ at $340 \mathrm{~nm}$, the shortest wavelength reported here. Additional errors occur during use of the lamp, as the lamp drifts away from set point conditions during short time scales and over several months the lamp ages and the calibration becomes less accurate. By averaging the spectra in time, random noise was reduced in the measurement over much of the spectral range. However, random noise is appreciable, especially above $800 \mathrm{~nm}$, though this noise level varies with test condition. Uncertainty can also be assessed by repeating the same test conditions on different days and observing how the measurements change. The same conditions were repeated as many as 4 times. While the relative spectral intensities were found to be repeatable to within 5-15\% the absolute intensities could vary run-to-run by as much as a factor of 2 . This point is discussed further below.

\section{Results}

\section{A. Flow over SiC test sample}

\section{Species identification}

Spectra obtained in three different test gases, Air-, $\mathrm{N}_{2^{-}}$and Mars-simulants are shown in Fig. 4. The spectra were obtained at the same nominal conditions corresponding to Runs 3, 5, and $7 \mathrm{a}$ in Table 2 . The measurement location was $2.2 \mathrm{~mm}$ in front of the sample. The air and $\mathrm{N}_{2}$ spectra have been arbitrarily scaled by constants (10, and 20, respectively) so they could be presented on the same graph with the Mars simulant. The relative intensities of these spectra will be discussed in detail in a subsequent section. Identification of atomic and molecular spectra was performed mainly from four different sources: the NIST Atomic Spectra Database, ${ }^{17}$ the reference book by Pearse and Gaydon, ${ }^{18}$ the thesis of Playez, ${ }^{19}$ and the paper by Park et al. ${ }^{20}$ In Fig. 4, selected bands (usually the lowest vibrational bands) are labeled in the figure with vertical hash marks indicating other bands that have been positively identified. Further bands may be clearly present in the spectra but could not be confirmed from the references and were therefore not indicated in the figure. A few species have been tentatively identified where emission peaks agreed with spectral lines of species that were known to be present in the flow, though detailed spectral signatures could not be compared with those from the literature. These are indicated by asterisks.

The red curve and red annotations in Fig. 4 indicate the Mars-simulant results. Species expected to be present include: $\mathrm{CO}_{2}, \mathrm{CO}, \mathrm{CN}, \mathrm{N}_{2}, \mathrm{~N}, \mathrm{C}, \mathrm{O}, \mathrm{C}_{2}$, and $\mathrm{Ar}$, and others. The Mars-simulant spectrum is dominated by emission between 340 and $425 \mathrm{~nm}$, which originates mainly from the well known CN Violet band. A peak near $451 \mathrm{~nm}$ was tentatively assigned to CO. The well-known Swan bands of $\mathrm{C}_{2}$ are responsible for emission between 455 and 565 $\mathrm{nm}$. CN red bands are observed between 570 and $650 \mathrm{~nm}$. Between 760 and $830 \mathrm{~nm}$, emission from the $\mathrm{C}_{2}$ Phillips Near IR band has been tentatively assigned, though some of the emission near $775 \mathrm{~nm}$ could be from a different species. O-atom emission may be present at $777.2 \mathrm{~nm}$ in the Mars emission spectrum, but the peak observed near this wavelength is at 776.4 which is nearly $1 \mathrm{~nm}$ to the blue, which is slightly larger than the observed wavelength accuracy of the spectrometer. Above $850 \mathrm{~nm}$, the data are noisier and while several emission bands appear to be present, none were conclusively assigned. No carbon atom emission lines were observed. ${ }^{21}$

The green and blue curves in Fig. 4 indicate air- and $\mathrm{N}_{2}$-simulants respectively. Species expected to be present in the $\mathrm{N}_{2}$ flow include $\mathrm{N}_{2}, \mathrm{~N}$, Ar and their ions. For the Air condition, additional species present include $\mathrm{O}_{2}, \mathrm{O}, \mathrm{NO}$, and their ions. Since the Air condition consists of a mixture of $\mathrm{N}_{2}, \mathrm{O}_{2}$ and $\mathrm{Ar}$ without the $\mathrm{CO}_{2}$ and water which naturally occur in air, hydrogen and carbon-containing species (notably, $\mathrm{CN}$ ) are not expected to be present. The Air and $\mathrm{N}_{2}$ spectra shown in Fig.4 are highly correlated, though the Air spectrum has twice the intensity of the $\mathrm{N}_{2}$ spectrum for the same nominal conditions (approximately the same enthalpy). This is puzzling because most of the features observed in the two spectra are the same and most of the emission originates from $\mathrm{N}_{2}, \mathrm{~N}_{2}{ }^{+}$and $\mathrm{N}$-atoms. For example, between 340 and $525 \mathrm{~nm}$, the spectra are dominated mainly by the $\mathrm{N}_{2}{ }^{+}$first negative (1-) system; between 340 and $360 \mathrm{~nm}$, there are strong contributions, probably from the $\mathrm{N}_{2}$ second positive system (2+). These bands have twice the intensity in the Air spectrum as in the $\mathrm{N}_{2}$ spectrum, despite the fact that there is actually less $\mathrm{N}_{2}$ in the Air test gas. This anomaly will be discussed further below. All the spectral features observed in the $\mathrm{N}_{2}$ spectrum also are present in the Air spectrum. These are indicated by black annotations in the figure. Many of these features are from atomic nitrogen, twelve of which are annotated in Fig. 4(b). In fact, many of these N-atom transitions have fine structure and nearby lines not indicated in the diagram. The resolution of the spectrometer is not high enough to resolve many of these transitions. Those labeled in Fig. 4(b) are somewhat arbitrary but tend to be the strongest lines in a region. However, a preference was also given in labeling for lines that are not overlapped with other transitions, such as $\mathrm{O}$-atoms. The Air spectrum shows several features not observed in the $\mathrm{N}_{2}$ or Mars spectra. These are attributed to O-atom electronic transitions and are shown in green. A few O-atom transitions that occur at the same wavelength as $\mathrm{N}$-atom transitions are indicated as vertical hash marks in green. Such spectral 
overlaps complicate quantitative analysis of air spectra for determining temperature, for example. Some welldefined, narrow peaks in the $\mathrm{N}_{2}$ and Air spectra have not been assigned. These may be from copper ions (for example, at 655.1 and $982.7 \mathrm{~nm}$ ) or other species that are present as contaminants. Very strong copper lines at 324.75 and $327.4 \mathrm{~nm}$ were observed at a variety of conditions, but these are not shown in the figures because they occur below $340 \mathrm{~nm}$.

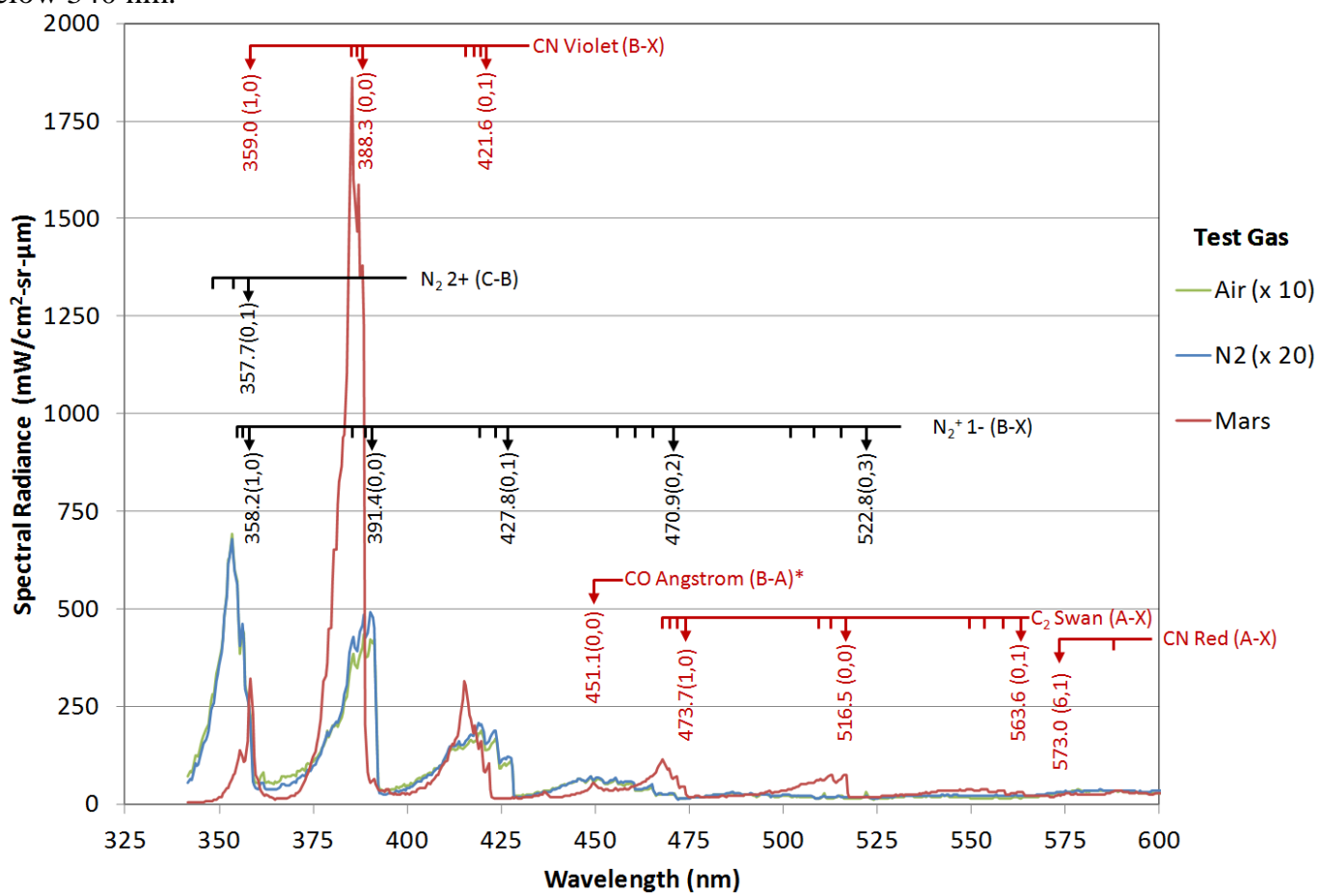

(a)

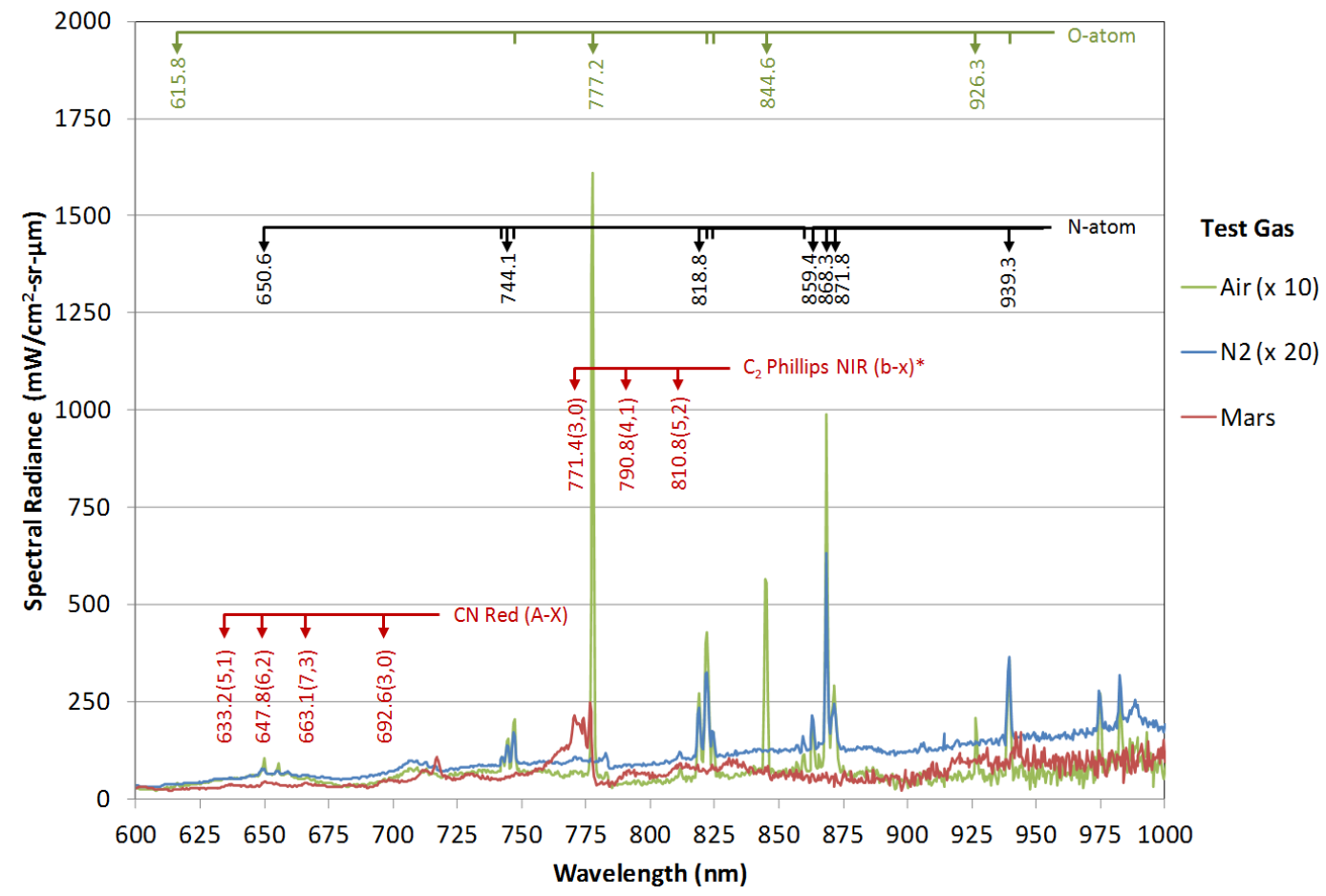

Figure 4. Emission spectra for Air, $\mathrm{N}_{2}$ and Mars simulants, obtained $2.2 \mathrm{~mm}$ in front of the $\mathrm{SiC}$ sample for nominally the same bulk enthalpy $(24 \mathrm{MJ} / \mathrm{kg})$. The Air spectral radiance has been multiplied by 10 while the $\mathrm{N}_{2}$ spectral radiance has been multiplied by 20 so the spectra can be observed on the same radiance scale. Annotation colors match the spectra they label, with black indicating features seen in both Air and $\mathrm{N}_{2}$ spectra. 


\section{Variation with enthalpy}

Two main results are shown as functions of enthalpy below: variation in spectra and variation in integrated signal intensity. The enthalpy of the flow was varied by varying the current to the arc jet while holding the gas flow rates fixed. This varied the arc pressure and static pressure as well as the enthalpy. Table 2 shows the flow properties for each test. Five different enthalpies were tested for each gas in order to study the effect of radiance and the variation in the spectral shapes with enthalpy. While varying the bulk enthalpy $\left(H_{\text {bulk }}\right)$, the same measurement location was maintained: $d=2.2 \mathrm{~mm}$ in front of the $\mathrm{SiC}$ sample and well inside the bow shock, which stands off at about 5-9 mm depending on the conditions (see below and also Ref. 2) Figures 5 and 6 show the resulting spectra on linear and logarithmic axes respectively.

(a)
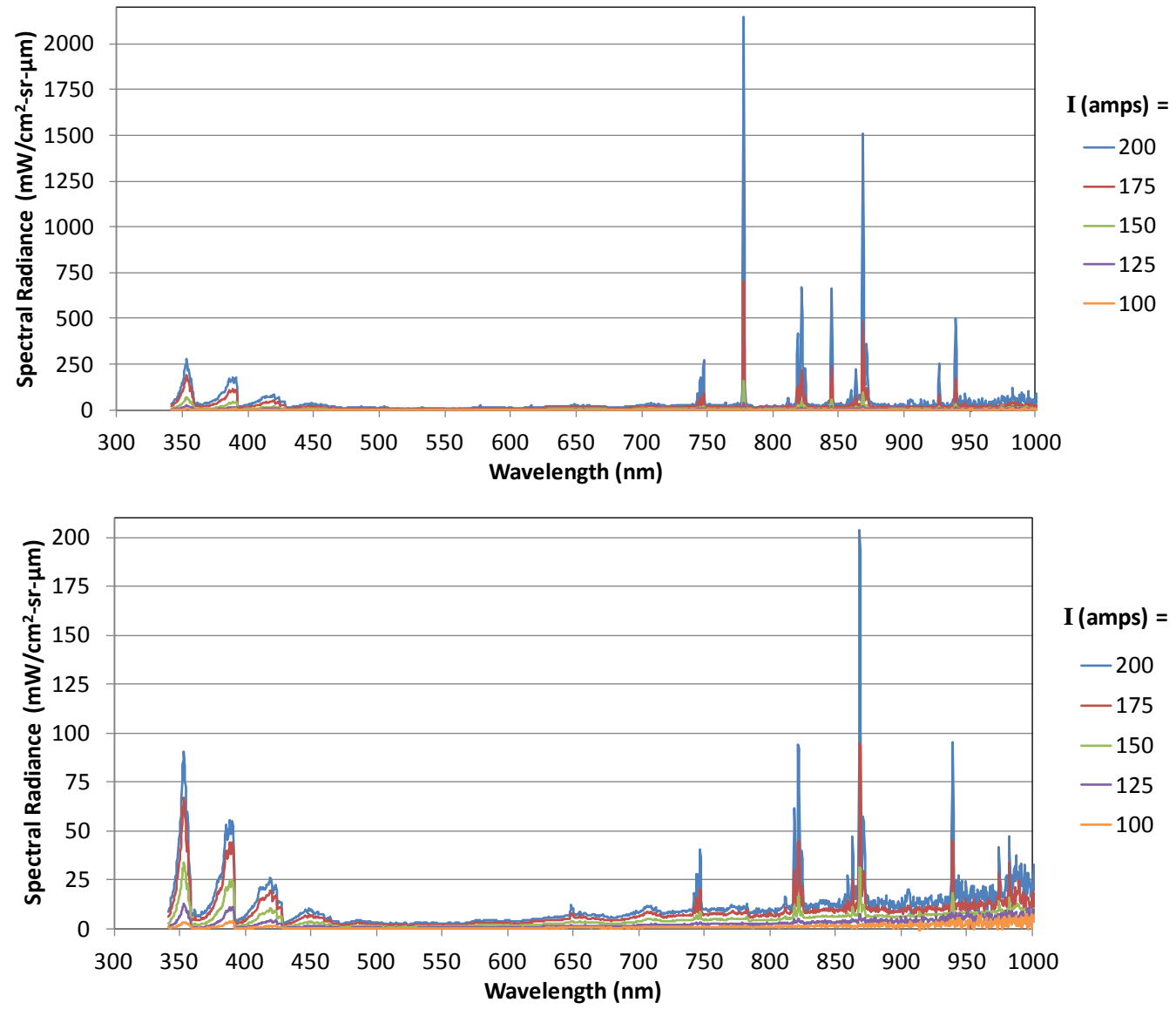

(b)

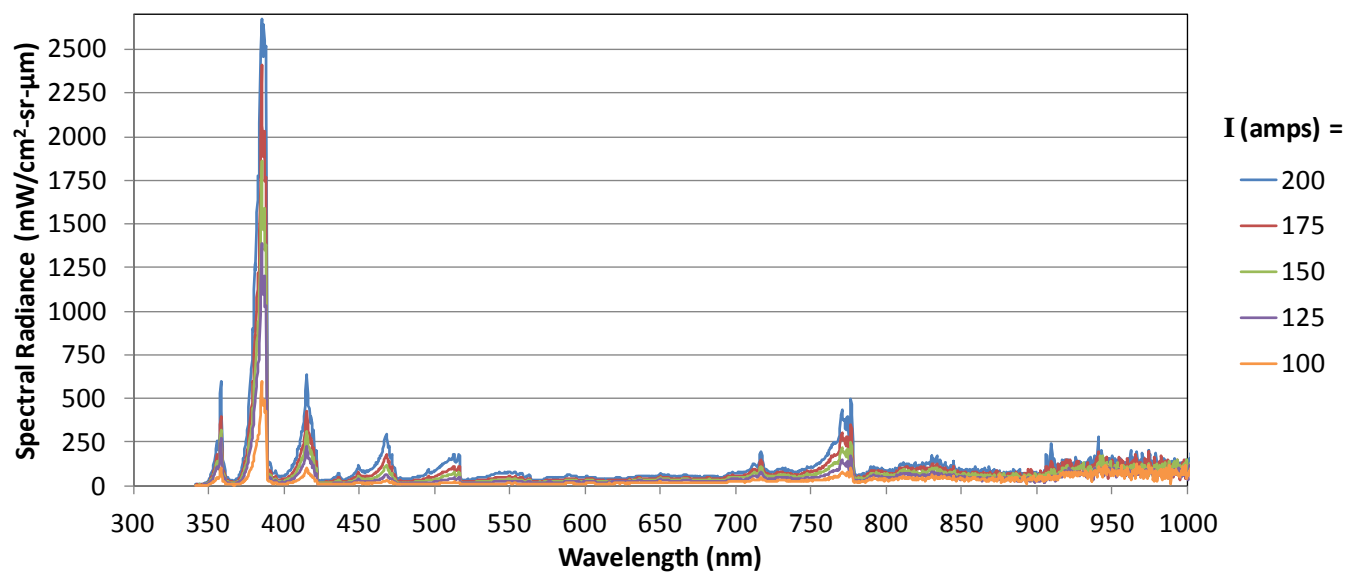

Figure 5. Emission spectra, graphed on a linear scale, of (a) Air, (b) $\mathrm{N}_{2}$ and (c) Mars simulants flow passing over the SiC sample, each shown as a function of the arc current, which corresponds to enthalpy (see Table 2). 


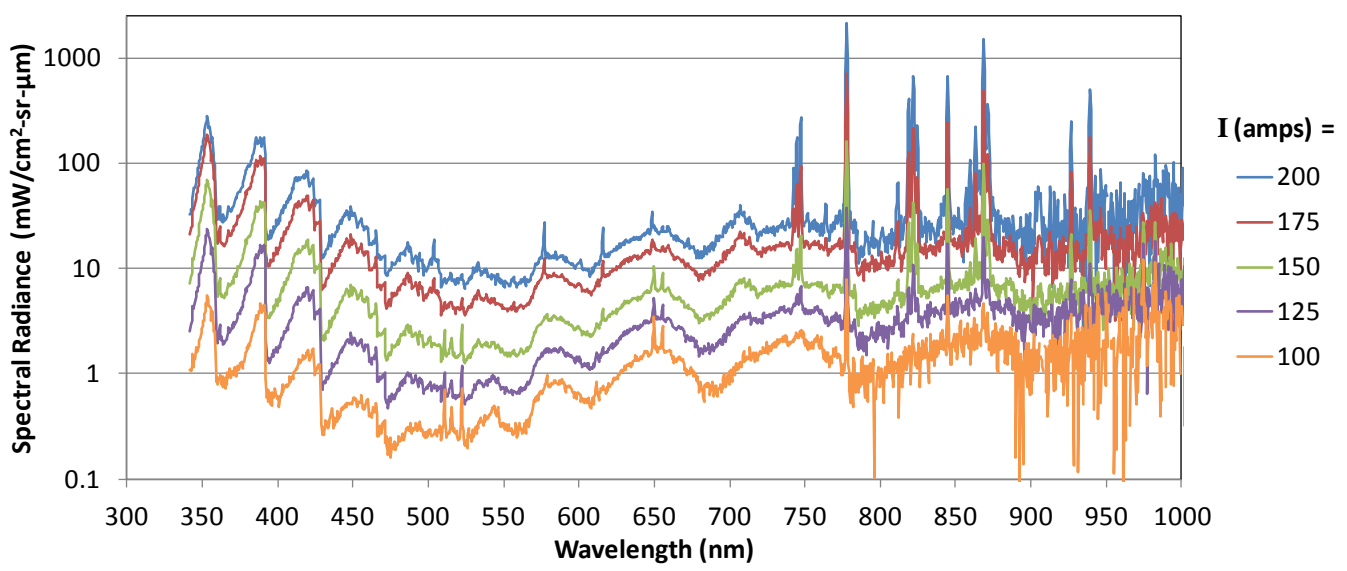

(a)

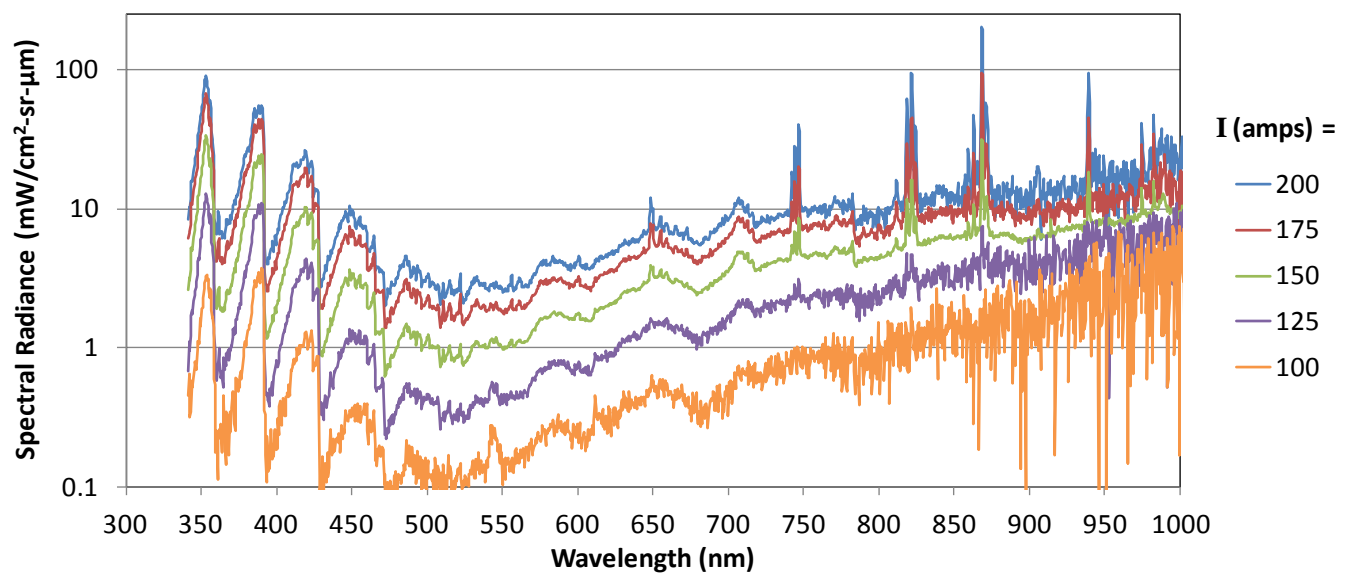

(b)

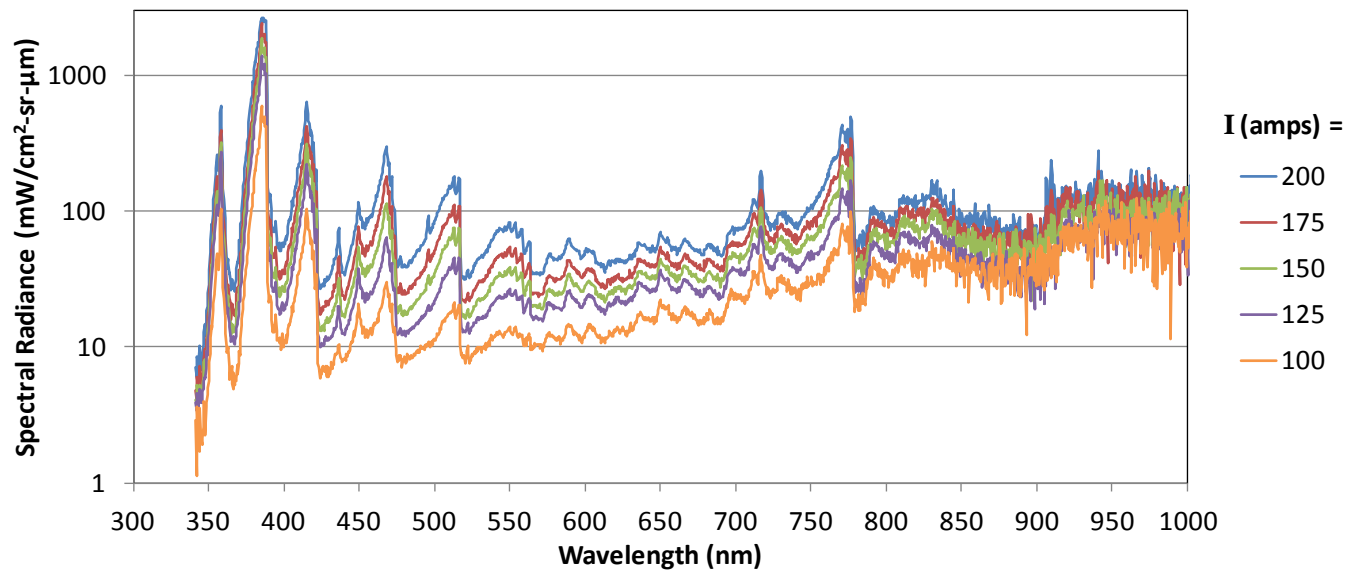

Figure 6. Emission spectra, graphed on a logarithmic sale, of (a) Air, (b) $\mathrm{N}_{2}$ and (c) Mars simulants flow passing over the SiC sample, each shown as a function of the arc current, which corresponds to enthalpy (see Table 2).

As expected, as the current (and therefore enthalpy) is increased, the spectral radiance increases. Figure 6 shows that increasing the enthalpy essentially scales up the intensity of the measured spectra. With the exception of some atomic lines, the spectra maintain a relatively constant shape as enthalpy is varied. Notable exceptions to this are weak $\mathrm{Cu}$ atomic lines observed near 511-522 and 650-655 nm in Fig. 6(a) and (b), the source of which is probably the facility's copper nozzle. These $\mathrm{Cu}$ lines decrease in relative intensity compared to the rest of the spectrum, as the flow enthalpy is increased. Above $740 \mathrm{~nm}$, many $\mathrm{O}$ - and $\mathrm{N}$-atom lines, which are excited electronic states, show an opposite trend: they increase in relative intensity as the flow enthalpy is increased. Figure 5 shows that the changes in intensity both of the intense $\mathrm{O}$ - and $\mathrm{N}$-atom lines as well as the observed molecular bands increase nonlinearly.

10

American Institute of Aeronautics and Astronautics 
For example, when the current (and enthalpy) doubles, the radiance in many cases increases by a factor of 10 or more. This trend is further investigated by computing the Total Radiance or integrated spectral radiance (defined as the average of the spectral radiance over 340-1000 nm and multiplying by the wavelength range, equal to $0.66 \mathrm{um}$, resulting in units of $\mathrm{mW} /\left(\mathrm{cm}^{2} \mathrm{sr}\right)$, where sr is steradian) and plotting this as a function of enthalpy and test gas composition (see Fig. 7). The radiance grows exponentially with enthalpy (straight lines on a semi-log plot), and faster for Air than for $\mathrm{N}_{2}$ or Mars simulants. This exponential growth can be explained by considering that the emission in all cases is originating from excited electronic states, whose populations are exponential (Boltzmann) functions of temperature. Since, to a first approximation, gas temperature increases linearly with flow enthalpy, excited state populations, and therefore radiation, which is proportional to excited state population, will increase exponentially with enthalpy.

For the same enthalpy, the Mars simulant has about an order of magnitude more radiance then Air. The Mars simulant contains both $\mathrm{CN}$ and $\mathrm{C}_{2}$ which are strong radiators, even when present in small quantities. Also, as mentioned above and as apparent in Fig. 7, for runs occurring one after another, Air has a about a factor of two higher radiation than the $\mathrm{N}_{2}$ simulant for a given enthalpy, despite the fact that most of the emission from air comes from nitrogen derivatives. Similar intensity increases have been observed in gas discharges when $\mathrm{O}_{2}$ is added to $\mathrm{N}_{2}{ }^{22}$ The addition of $\mathrm{O}_{2}$ increased the intensity of emission from $\mathrm{N}_{2}$ first positive, second positive and $\mathrm{N}_{2}{ }^{+}$first negative bands. The authors attribute this to a collisional intermolecular energy transfer between $\mathrm{O}_{2}$ excited states and select $\mathrm{N}_{2}$ states. Note also that much of the radiation from an arcjet flow comes from the UV spectral region below $340 \mathrm{~nm}$ and the vacuum ultraviolet, not reported here.

Comparing Fig. 7 with Table 2, for an enthalpy of 20-21 MJ/kg, $\mathrm{N}_{2}$ has the highest heat flux (as measured by a cold slug calorimeter) and the pyrometer indicates that the $\mathrm{SiC}$ sample is the hottest $\left(1670{ }^{\circ} \mathrm{C}\right) . \mathrm{N}_{2}$ also has the lowest total radiance of the three cases. The Air simulant produces an intermediate level of heat flux, an intermediate level of radiance and the lowest surface temperature $\left(1440{ }^{\circ} \mathrm{C}\right)$. The Mars simulant by far produces the most radiance, has an intermediate surface temperature $\left(1510^{\circ} \mathrm{C}\right)$ and the lowest heat flux. A careful analysis of the convective, conductive and radiative (both from the gas and the sample) heat transfer is required to fully understand these relationships.

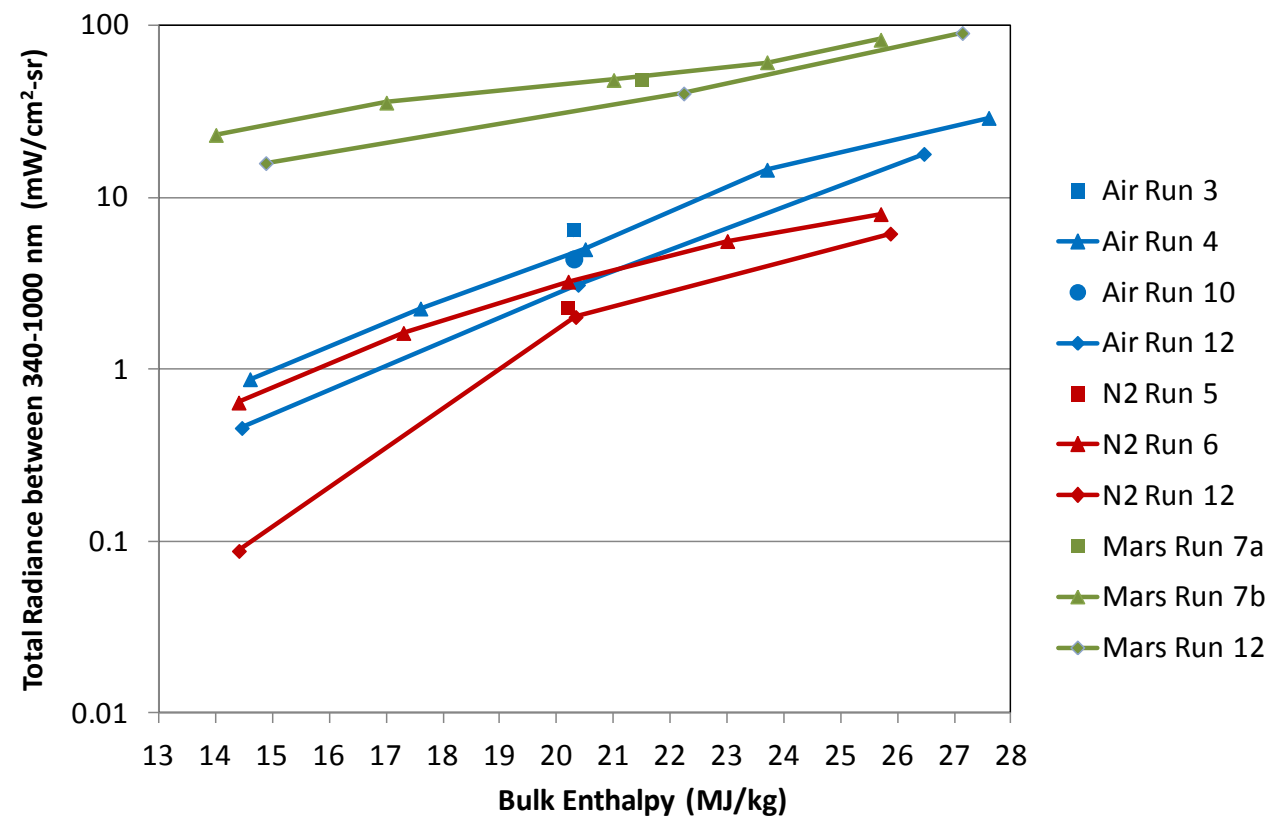

Figure 7. Variation of total radiance with bulk enthalpy, where total radiance is defined as the spectral radiance integrated between 340 and $1000 \mathrm{~nm}$. Measurements were made at a fixed position in front of the sample, as indicated in Table 2 . For Runs 3, 5, 7a, and 10 the measurements were reported between 2 and $2.5 \mathrm{~mm}$ in front of the sample.

Figure 7 also shows a troubling trend: repeated runs at the same conditions do not yield the same absolute radiance. Consider, for example, tests performed in Air at $152 \mathrm{amps}, \sim 20 \mathrm{MJ} / \mathrm{kg}$, with measurements obtained between $d=2$ and $2.5 \mathrm{~mm}$ in front of the sample: Fig. 8 shows four spectra obtained at these repeated conditions, resulting in a spread of (blue) points in Fig. 7. It appears that for each subsequent run in which the measurement was made, the radiance was about $20-25 \%$ lower. The final spectrum (Run 12) is about half the intensity of the first. 
If the peaks are normalized to each other, they agree to within 5-15\% over most of the spectral range. One might suspect that this change in intensity with time could be associated with facility windows becoming dirty, a drifting calibration in the detection system or perhaps damage to the detector. However, the spectrometer intensity was recalibrated between Runs 10 and 12 (at that time the system was being prepared for testing PICA samples so the aperture was reduced which lowered the signal intensity in Run 12, leading to more noise in that spectrum compared to the others). Investigations of the $\mathrm{N}_{2}$ and Mars simulants mostly show a similar trend (also seen in Fig. 7): later runs at repeat conditions generally have lower intensities. However, this opposite is sometimes true (e.g. $\mathrm{N}_{2}$ Run 6 showed more emission than $\mathrm{N}_{2}$ Run 5, though as indicated in Table 2, the measurements in Run 6 were obtained closer to the sample than Run 5 and may therefore may have contained some blackbody radiation from the sample.) However, small variations in the measurement location (for example, $\pm 0.5 \mathrm{~mm}$ when measuring at $d=2.2 \mathrm{~mm}$ ) are not likely to be responsible for these anomalous large (factor of 2) changes in radiance, because it will be shown below that the intensities of the emitted spectra stay fairly constant in the range of $d=1$ to $3 \mathrm{~mm}$ in front of the sample. Another possible explanation for this trend is that the facility operating conditions could be changing. However, examining Table 2, the facility is very repeatable in its set points with most parameters having better than $1-3 \%$ repeatability. One correlation that may explain the systematic trend is that the sample temperature, as measured by the pyrometer, generally showed a decreasing trend as run number increased. For Air, the temperature decreased from 1440 to $1390{ }^{\circ} \mathrm{C}$ over the course of these runs (Runs 10 and 12 having the same temperature). Radiation depends nonlinearly on gas temperature and the gas temperature is affected by the surface temperature. So, a changing sample temperature can affect the measured radiance.

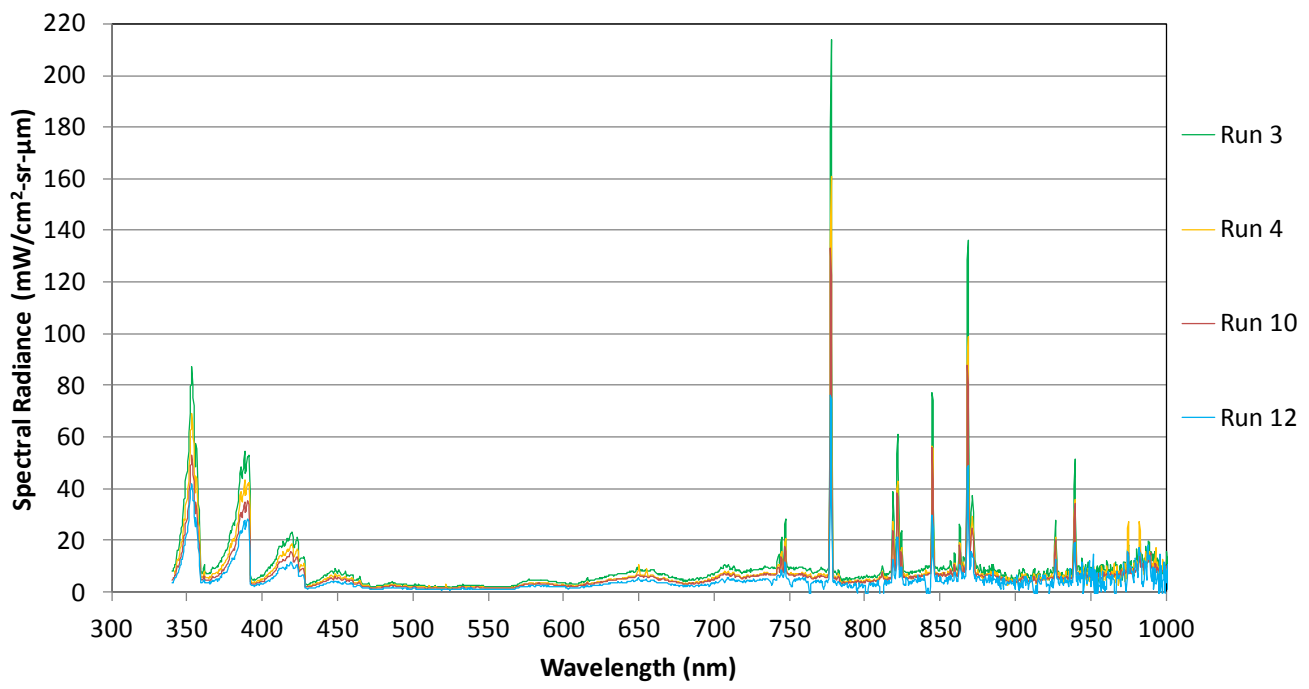

Figure 8. Four runs repeating the same flow conditions: Air simulant flowing over $\mathrm{SiC}$ at an enthalpy of $20 \mathrm{MJ} / \mathrm{kg}, d=2.2 \pm 0.3$ $\mathrm{mm}$. Runs 2, 4 and 10 used the same spectrometer intensity calibration. The aperture was reduced and the spectrometer was recalibrated between Runs 10 and 12 .

Additional evidence that the surface temperature affects the intensity of the emission can be obtained by looking at the time history of a single run. Figure 9 shows several of the flow parameters measured by the data system as a function of time during Run 12 in which the enthalpy was varied. This part of the run used the Mars simulant test gas. The flow parameters, shown as lines in the plot, are steady during the run, usually to within $1 \%$. The only facility-measured parameter that varies significantly during the run is the temperature of the sample surface, measured with a pyrometer. When the sample is first injected it is relatively cool and it takes about 20 seconds to achieve steady state. Emission from three different species (shown as dots) suddenly jumps and then falls by a factor of 2.5 during this $20 \mathrm{~s}$ transient. Eventually a more steady level is reached, but even when the pyrometer temperature is relatively constant the species emission varies significantly (suggesting that the sample temperature is not the only cause of this time variation). All three species shown have intensities that vary by $10-20 \%$ even while the facility operates at a steady state. Presently, the reason for these within-run and run-to-run trends in the emission is unexplained. 


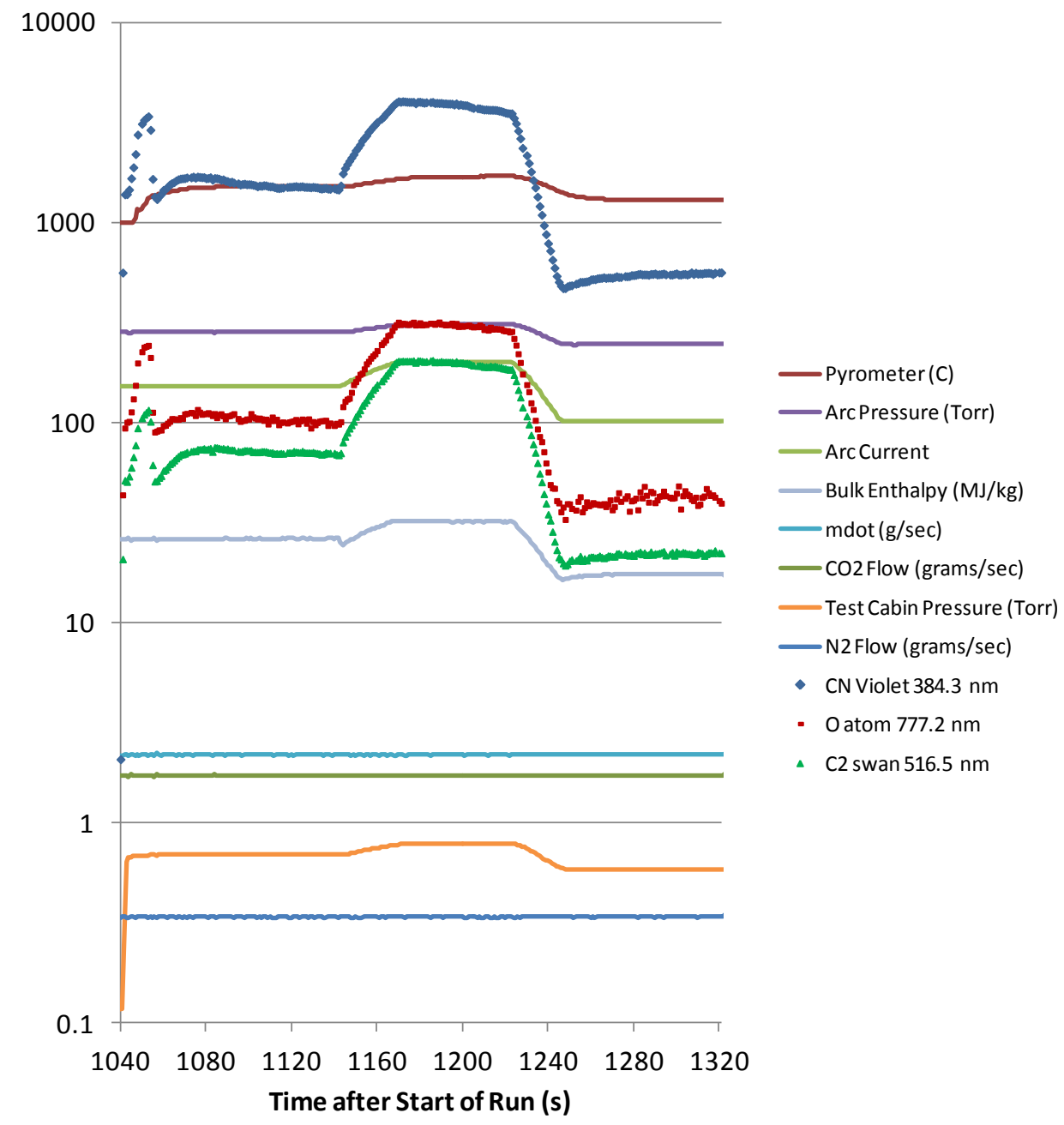

Figure 9. Selected flow parameters (lines) and spectral radiance (symbols) for Run 12, Mars Atmosphere. The facility was at steady operating conditions ( $\operatorname{arc}$ current $=152 \mathrm{~A}, \mathrm{H}_{\text {bulk }}=22 \mathrm{MJ} / \mathrm{kg}$ ) prior to the sample being injected at $1042 \mathrm{~s}$. The condition changes to a higher enthalpy condition (arc current $=201 \mathrm{~A}, \mathrm{H}_{\text {bulk }}=27 \mathrm{MJ} / \mathrm{kg}$ ) at about $1170 \mathrm{~s}$ and then to a lower enthalpy condition (arc current $=102 \mathrm{~A}, \mathrm{H}_{\text {bulk }}=15 \mathrm{MJ} / \mathrm{kg}$ ) at about $1260 \mathrm{~s}$. The flowrate of gases (mdot) is constant at $2.19 \mathrm{~g} / \mathrm{s}$.

3. Spatial distribution of species

A stepper motor was used to translate the fiber horizontally, which moved the measurement location in the $\mathrm{x}$ direction, perpendicular to the test sample. Calibration experiments were performed to account for the magnification of the optical system so that a given translation of the fiber resulted in a known distance, $d$, from the sample surface. Figure 10 shows measurements obtained at different positions in front of the sample. Figure 10(a) shows that when the fiber is at a negative $d$, a broad continuum is observed because the fiber is seeing the greybody radiation from the test article itself. A position of $d=0$ is expected to have a small amount of blackbody radiation present. Positive positions greater than one half the probe volume width (the diameter of the fiber magnified by the optical system, roughly $1 \mathrm{~mm}$ ) should have no continuum radiation from directly looking at the sample. However, the fiber may collect spurious blackbody (and other) radiation reflected from the walls inside the test chamber.

For the case of Air, Figs. 10(a) and (b) show that as the distance from the model surface increases, all of the atomic lines and molecular bands initially increase in intensity, reaching a maximum at about $3 \mathrm{~mm}$ from the sample. The lower concentrations, particularly of O-atoms, near the surface of the sample could either be caused by chemical reaction with the $\mathrm{SiC}$ sample (consumption of $\mathrm{O}$-atoms to form $\mathrm{SiO}$ or $\mathrm{SiO}_{2}$ ) or simply caused by cooling by the relatively cooler test sample which reduces the gas temperature, and consequently the excited-state atomic populations. After reaching maximum values, the intensities then drop continuously between about 4 and 9 mm. The atomic concentrations reach a steady value at values slightly greater than $10 \mathrm{~mm}$ from the surface while the molecular $\mathrm{N}_{2}{ }^{+}$emission continues to drop until nearly $14 \mathrm{~mm}$. The decrease in emission between 4 and $9 \mathrm{~mm}$ is 
most likely associated with the bow shock in front of the sample. A bow shock is expected to cause an instantaneous discontinuity in flow properties. Such sharp discontinuities were observed in this facility using NO PLIF, which is an imaging technique with sub-microsecond time resolution. ${ }^{2}$ The NO PLIF showed unsteady motion of the bow shock wave. The current measurements are time-averaged for a minimum of $3 \mathrm{msec}$ and up to 30 seconds. Unsteady flow features, such as unsteady shockwave motion, are blurred out. Thus, the gradual decrease in emission intensity likely provides an indication of the flow unsteadiness. The half-way point in the intensities can be used to determine an effective shock stand-off distance. For the case of air, this is $5.5 \pm 0.5 \mathrm{~mm}$. Because of this unsteadiness, this instrument is unlikely to be able to measure nonequilibrium phenomena downstream of the shock wave. A more sophisticated high-speed spectral imaging apparatus could make such measurements. ${ }^{23}$ Much of the radiance observed in the freestream $(d>10 \mathrm{~mm})$ in Figs. 10-11 is probably collection of reflected light from inside the test chamber rather than actual freestream emission. Measurements obtained in the freestream with the sample removed showed much lower levels of radiance than observed for $d>10$ in Figs. 10 and 11. For example, with the sample removed, the 777.2 O-atom line showed a radiance of only $1 \mathrm{~mW} /\left(\mathrm{cm}^{2}-\mathrm{sr}-\mu \mathrm{m}\right)$ whereas Fig. 10(b) shows a value of $7 \mathrm{~mW} /\left(\mathrm{cm}^{2}-\mathrm{sr}-\mu \mathrm{m}\right)$.

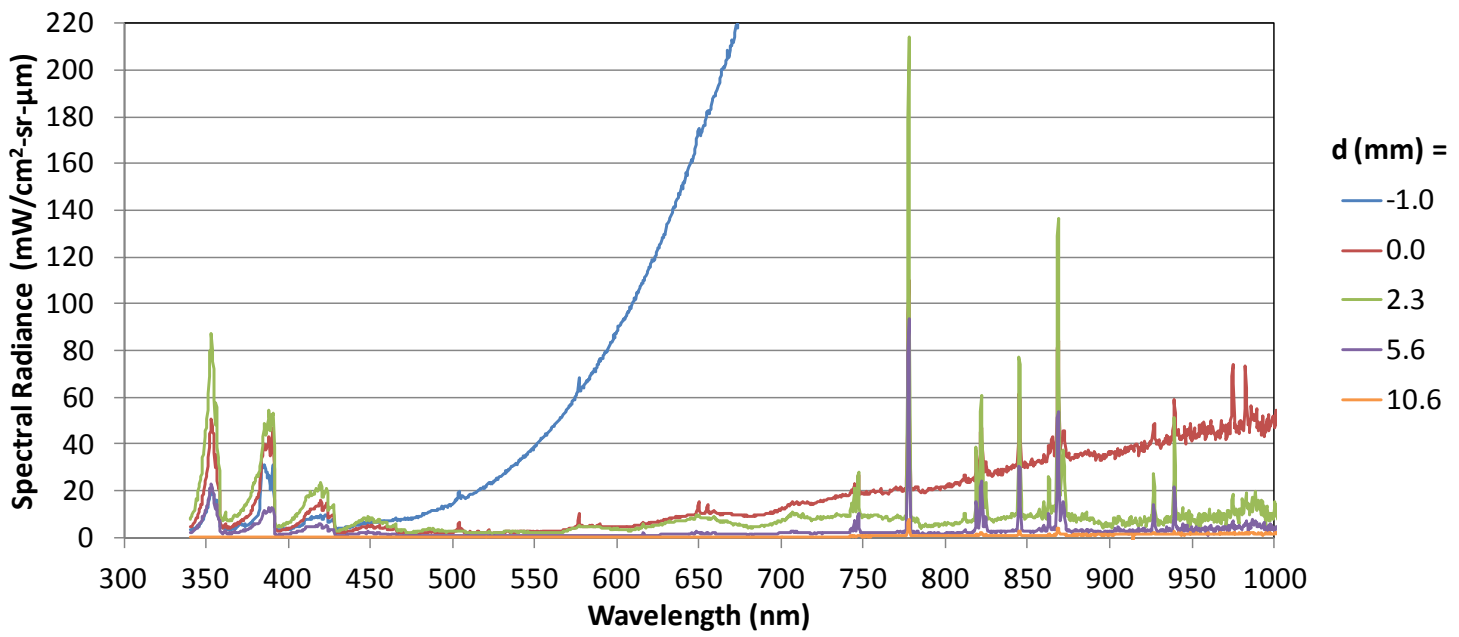

(a)

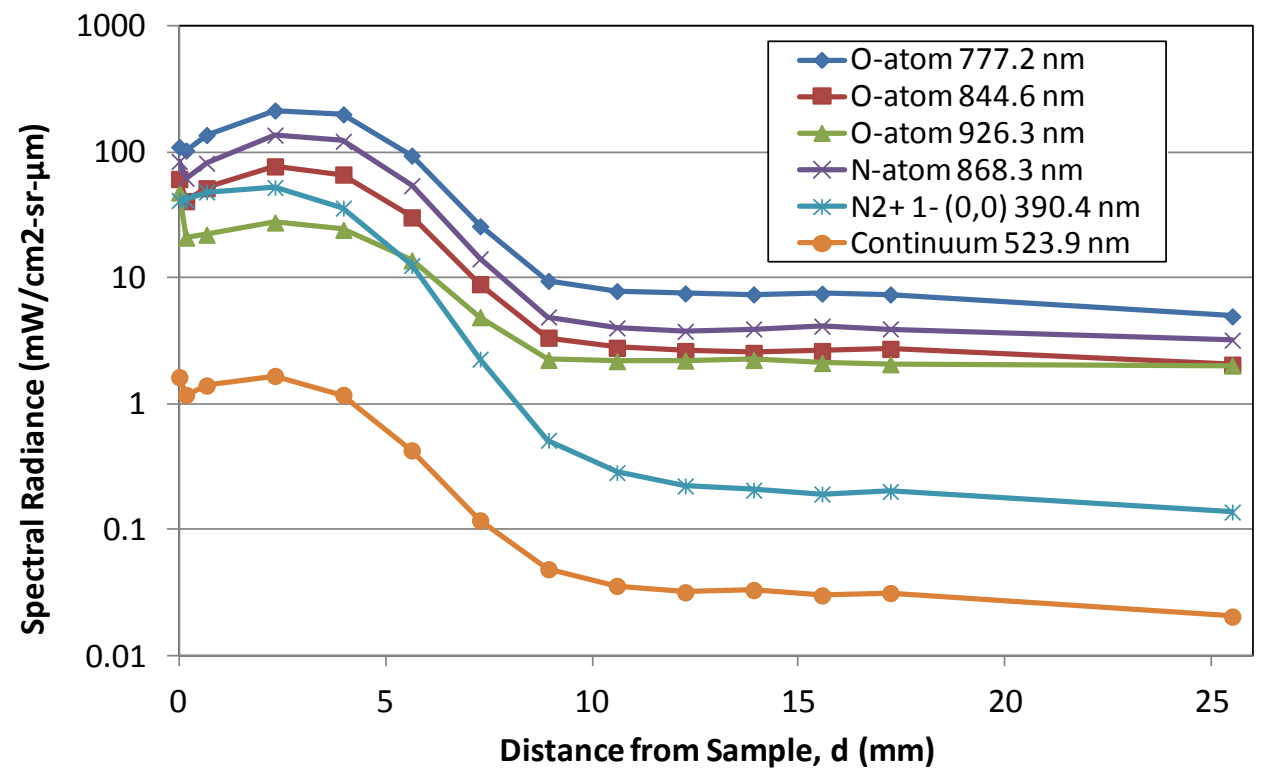

(b)

Figure 10. Variation of emission spectra for Air: arc current $=150 \mathrm{amps}$, bulk enthalpy $=24 \mathrm{MJ} / \mathrm{kg}$. Top panel (a) shows spectra at selected distances from the sample, $\mathrm{d}$, while bottom panel (b) shows variation of specific lines and bands with $d$.

The results for the $\mathrm{N}_{2}$ flow, shown in Fig. 11, are qualitatively similar to Air. Measurements further from the sample show a slight increase in $\mathrm{N}$-atom emission, peaking around $4 \mathrm{~mm}$ from the surface. Similar to the case of air, 
the $\mathrm{N}_{2}{ }^{+}$emission stays relatively more constant in the shock layer and more dramatically decreases with distance from the sample. The shock standoff distances for the cases of Air and $\mathrm{N}_{2}(5.6 \pm 0.5 \mathrm{~mm})$ agree. A significant difference in the two cases is that the ratio of the $\mathrm{N}$-atom $868.3 \mathrm{~nm}$ line to the $\mathrm{N}_{2}{ }^{+}$band shown in the graphs is very different. For Air at $d=2.3 \mathrm{~mm}$, the ratio is 2.6 while for $\mathrm{N}_{2}$ it is 0.8 . There is relatively more $\mathrm{N}_{2}{ }^{+}$emission in the $\mathrm{N}_{2}$ case than in the air case. This higher emission from $\mathrm{N}_{2}$ ions could be explained by different gas temperatures in the two experiments.

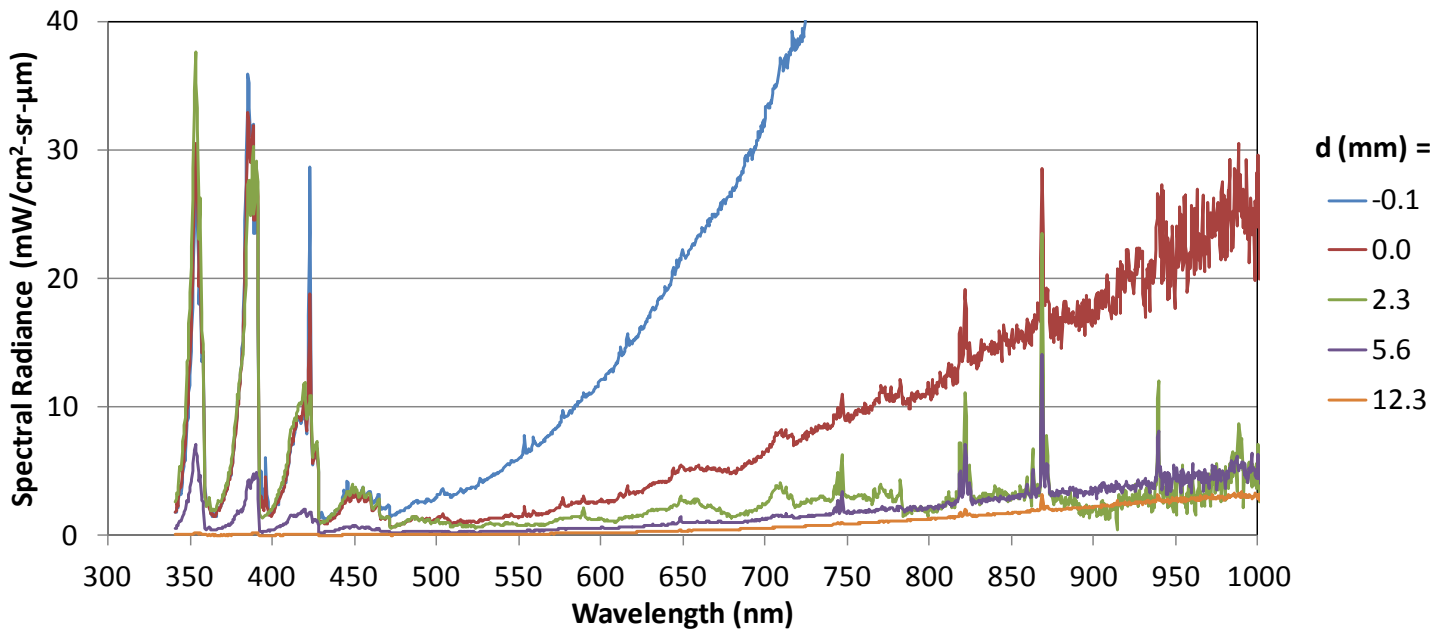

(a)

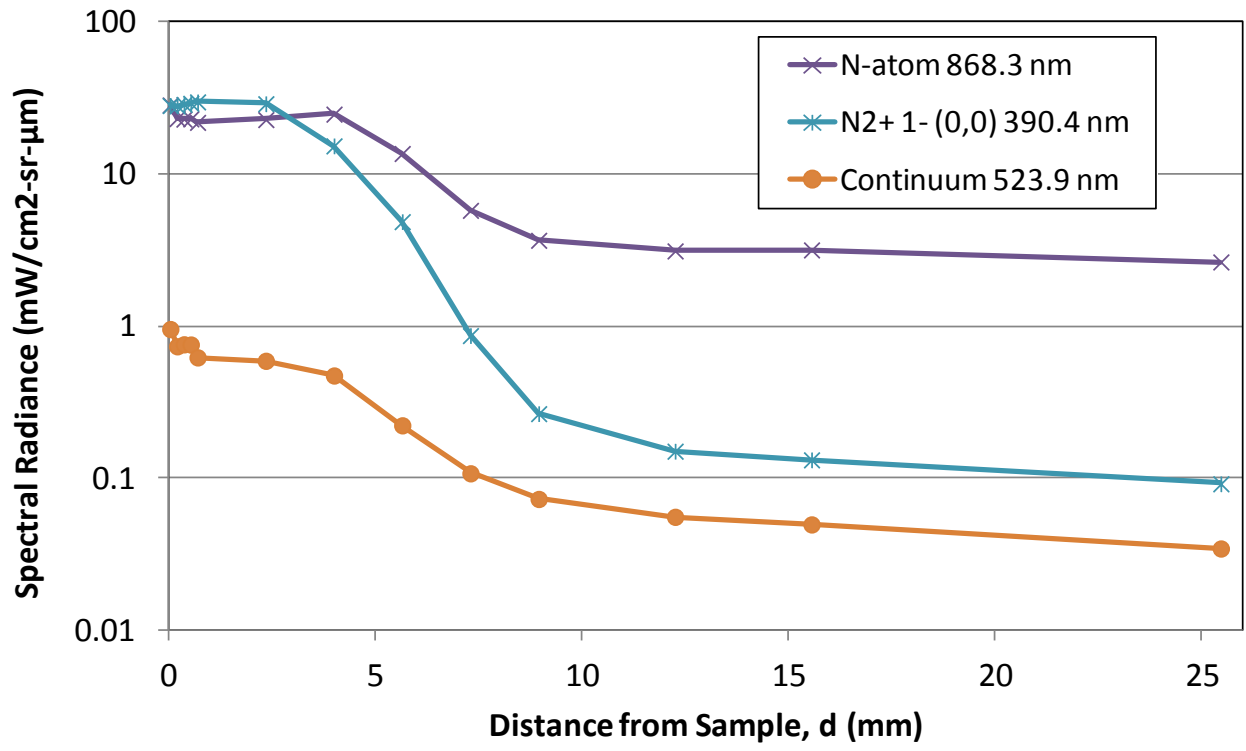

(b)

Figure 11. Variation of emission spectra for $\mathrm{N}_{2}$ : arc current $=150 \mathrm{amps}$, bulk enthalpy $=24 \mathrm{MJ} / \mathrm{kg}$,. Top panel (a) shows spectra at selected distances from the sample, $d$, while bottom panel (b) shows variation of specific lines and bands with $d$.

The spatial variation in the measurements show some different qualitative trends in the case of the Mars simulant, as shown in Fig. 12. First, the emission has a large spatial region between 1 and $5.5 \mathrm{~mm}$ where most of the emission bands have a constant intensity, unlike the Air and $\mathrm{N}_{2}$ cases above, where a peak value is observed far from the sample surface. One molecular band, the $\mathrm{C}_{2}$ swan band, differs slightly from this trend in the figure: it shows a gradual increase in emission in the first few $\mathrm{mm}$ from the surface, but between 2.3 and $5.5 \mathrm{~mm}$ it levels off. Another trend that differs from Air and $\mathrm{N}_{2}$ is that the drop in emission at the edge of the bow shock is more severe in the Mars simulant case. Most of the emission bands drop 1.5 decades on the log scale between the 5.6 to $8.9 \mathrm{~mm}$ measurement locations, whereas for Air and $\mathrm{N}_{2}$, the emission only drops by 1 decade for most of the species, over the same range. This may be an indication that the shock position is more stable in the Mars simulant case. 
Alternately, it is possible that these strongly radiating species $\left(\mathrm{CN}\right.$ and $\left.\mathrm{C}_{2}\right)$ depend more strongly on temperature and more clearly delineate the higher temperature shock layer. The bow shock standoff distance for the Mars case $(4.8 \pm 0.5 \mathrm{~mm})$ is smaller than in Air and $\mathrm{N}_{2}$. The sudden increase in emission within $1 \mathrm{~mm}$ of the surface of the sample for the bands $>520 \mathrm{~nm}$ in Fig 12(b) is almost certainly caused by continuum emission entering the fiber. While this effect may be actual continuum emission from the flow, it is probable that it could be an artifact of the experiment: part of the field of view of the fiber may be viewing the sample and it is possible that the origin $(d=0)$ was assigned slightly differently in this case compared to prior cases.

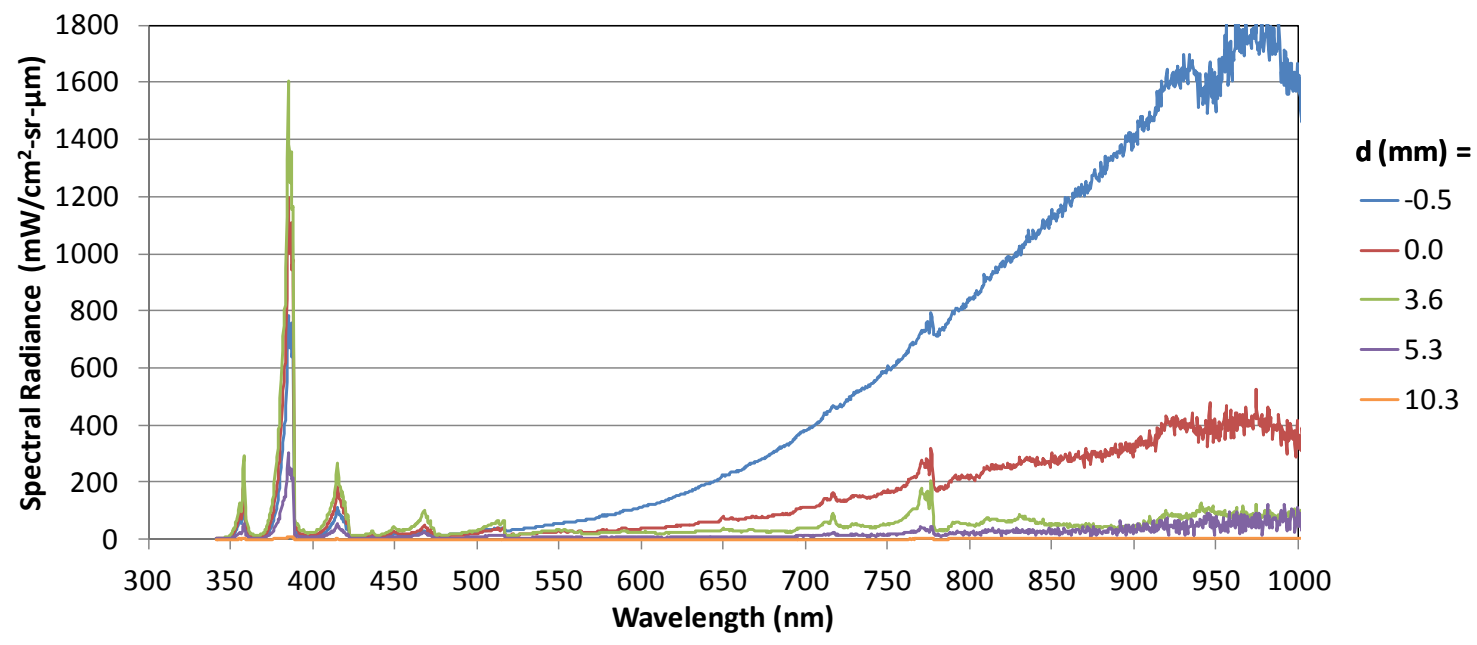

(a)

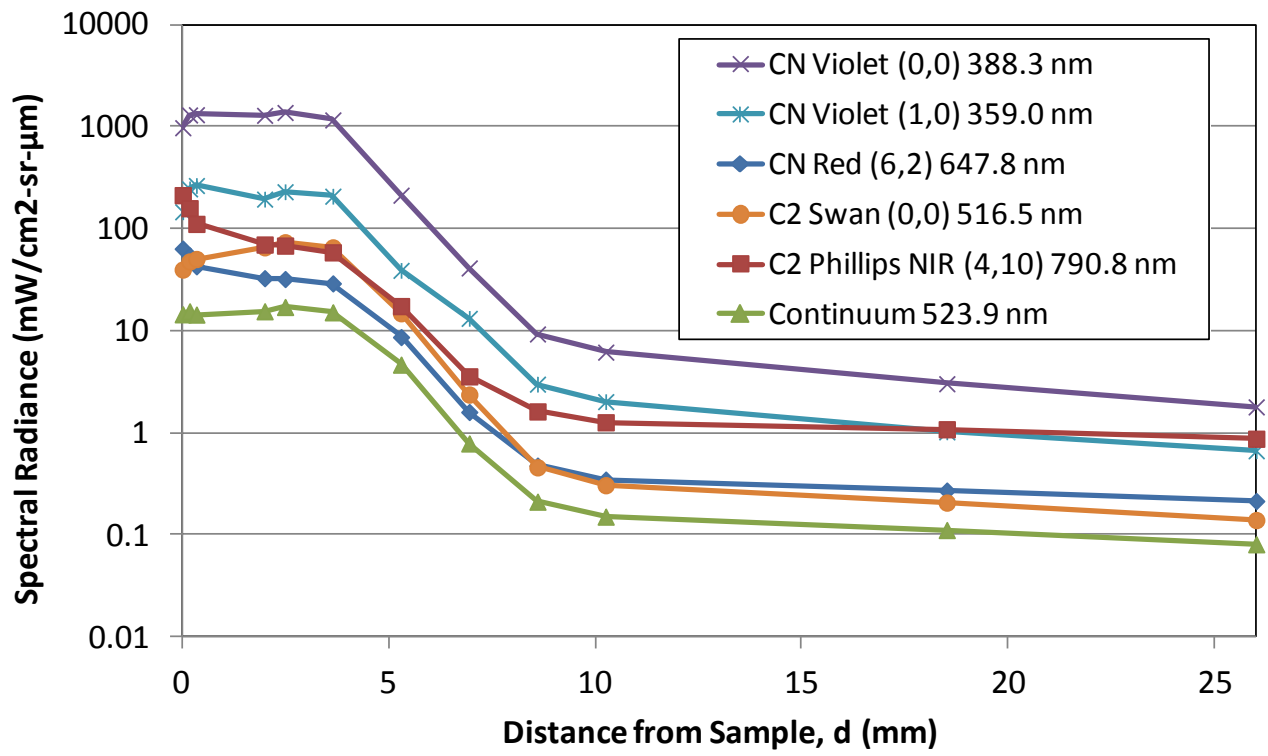

(b)

Figure 12. Variation of emission spectra for Mars: arc current $=150 \mathrm{amps}$, bulk enthalpy $=25 \mathrm{MJ} / \mathrm{kg}$,. Top panel (a) shows spectra at selected distances from the sample, $d$, while bottom panel (b) shows variation of specific lines and bands with $d$.

\section{B. Flow over PICA test sample}

1. Species identification

Only one run is presented herein testing the PICA heatshield material. The Air-simulant test gas was used at an enthalpy of $45 \mathrm{MJ} / \mathrm{kg}$ (see Table 2). This is roughly double the enthalpy used in the SiC runs described above. Consequently the emission intensity is much higher. A sample spectrum is shown in Fig. 13 for a measurement location of $d=2.2 \mathrm{~mm}$. The task of assigning species is relatively more difficult when an ablative target is studied because more species may be present. Species expected to be present include $\mathrm{N}_{2}, \mathrm{~N}, \mathrm{NO}, \mathrm{O}, \mathrm{O}_{2}, \mathrm{Ar}$ and their ions from the air simulant test gas as well as $\mathrm{C}, \mathrm{H}$ and species resulting from the combination of these species with air products $(\mathrm{CN}, \mathrm{CO}, \mathrm{CH}, \mathrm{OH}$, etc.) Furthermore, trace species added during the manufacture of the heatshield 
material or possibly contaminants from the facility may be present. Thus, the assignment of species can, in some cases, be speculative. Assignments might be improved if the chemical composition of the PICA material were freely available.

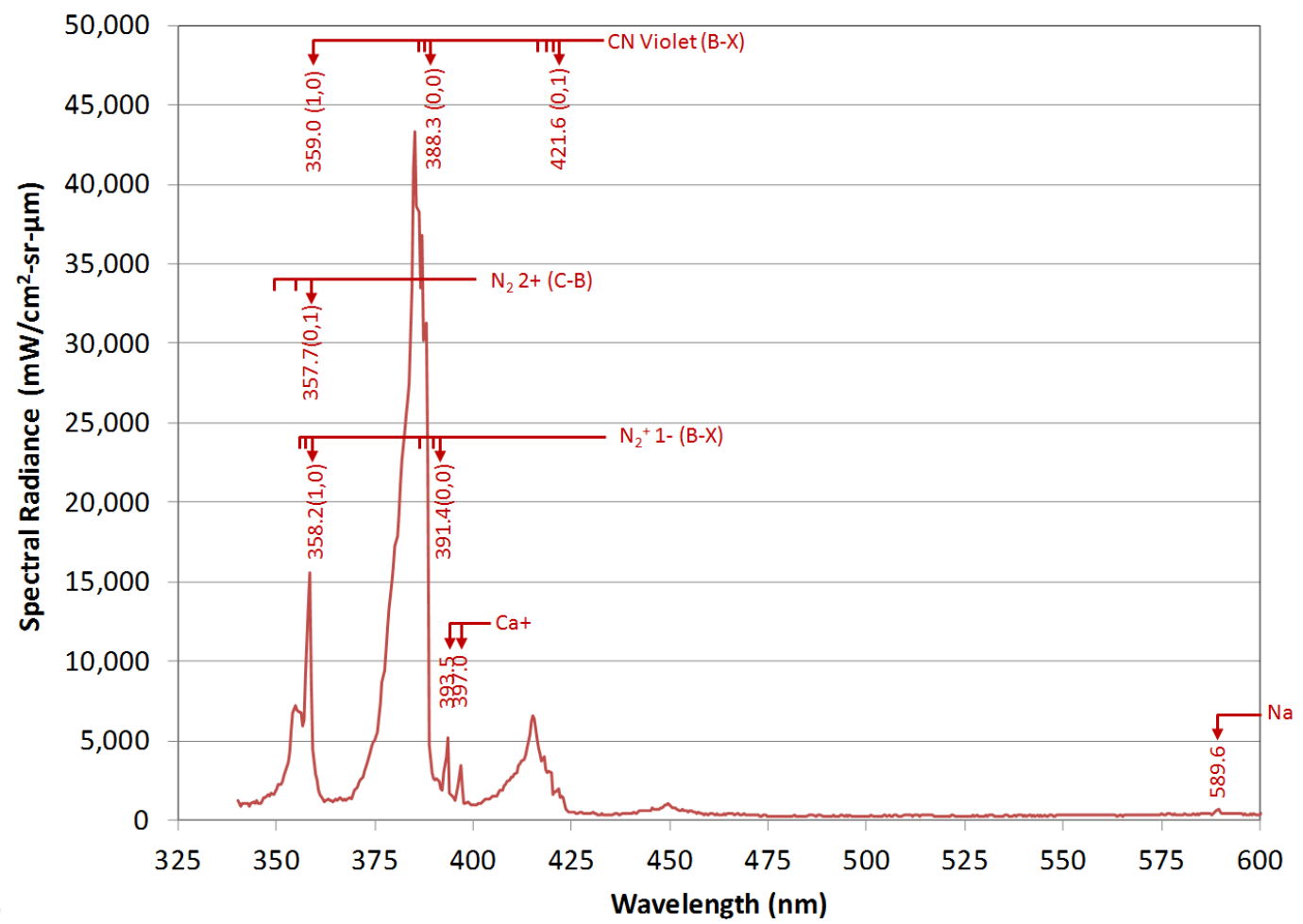

(a)

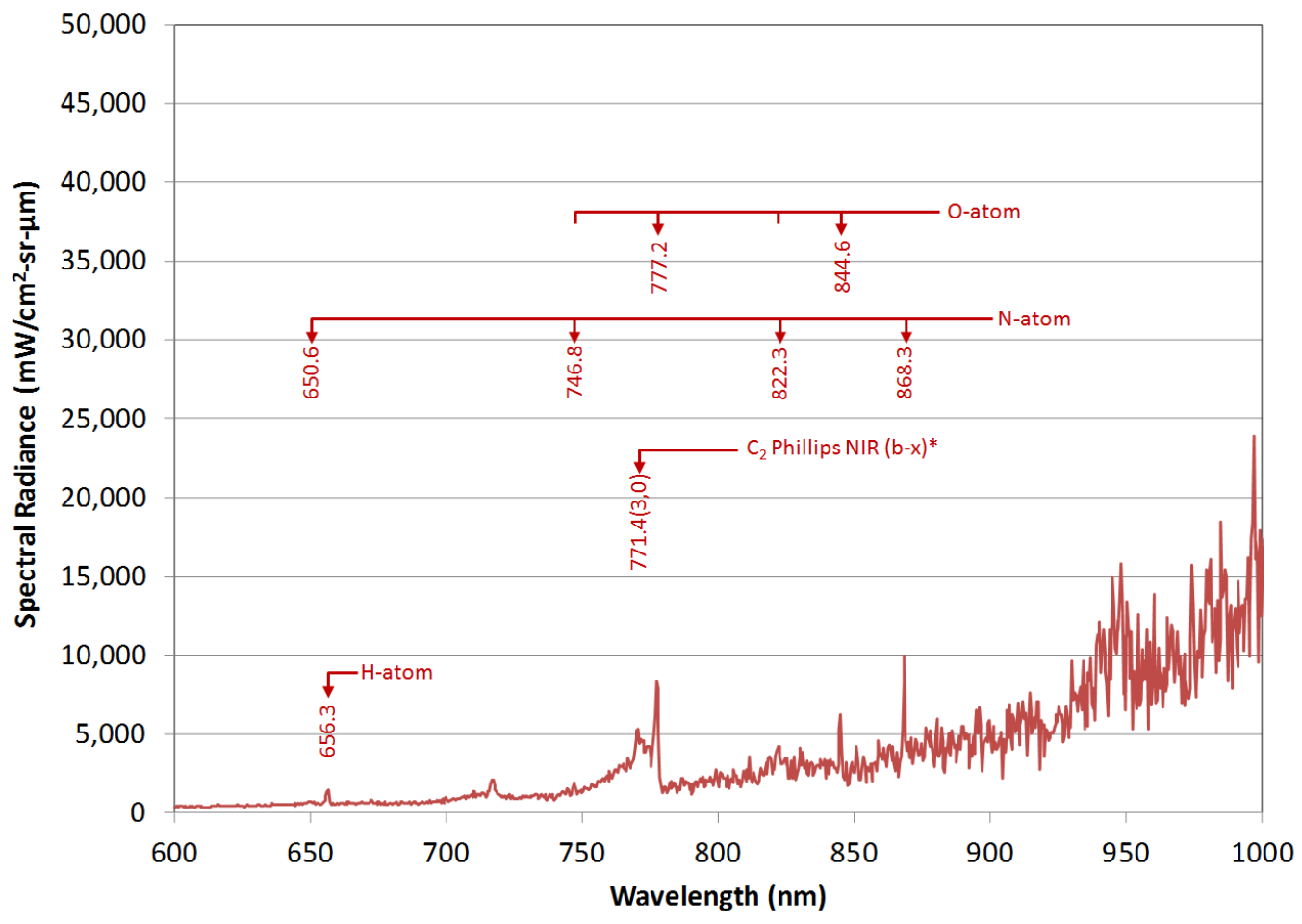

(b)

Figure 13. Detailed spectral radiance observed in Run 6 with the Air simulant gas flowing over a PICA test sample. Selected atomic and molecular lines are labeled. This is an average of 6 spectra obtained within $2.2 \pm 0.3 \mathrm{~mm}$ in front of the sample.

In general, the spectra show qualitative similarity to the Mars spectra shown in Figs. 4, 5(c) and 12, despite the fact that the test gas was air. This indicates a significant mixing of ablation gases (containing carbon) with the 
heated air (containing nitrogen). For example, strong radiation from $\mathrm{CN}$ Violet is observed and this emission dominates the radiance. A strong band between 760 and $776 \mathrm{~nm}$ (perhaps $\mathrm{C}_{2}$ Phillips) is again present as is O-atom emission at $777.2 \mathrm{~nm}$ and a few other wavelengths. Various $\mathrm{N}$-atom lines are observed as indicated in Fig. 13. Some weak $\mathrm{N}_{2}{ }^{+} 1$ - bands are observed and some $\mathrm{N}_{2} 2+$ bands may be present, overlapped with $\mathrm{CN}$ emission. These spectra resemble measurements obtained during the Earth entry of the Stardust capsule in 2006, which were fit with a theoretical model to determine temperatures from both $\mathrm{CN}$ and $\mathrm{N}_{2}{ }^{24}$

We also observe several differences between the spectrum in Fig. 13 and those obtained in Mars simulants. Neither $\mathrm{C}_{2}$ Swan bands nor CN Red bands are observed. The absence of the stronger $\mathrm{C}_{2}$ Swan bands suggests that the band between 760 and 776 is not $\mathrm{C}_{2}$ Phillips. Several lines not present in the Mars spectrum appear in Fig. 13. An example is a line observed at $589.6 \mathrm{~nm}$ which is probably sodium $(\mathrm{Na})$ though it might possibly be ionized copper $\left(\mathrm{Cu}^{+}\right)$. A pair of lines near $395 \mathrm{~nm}$ are present. These have been attributed to ionized calcium $\left(\mathrm{Ca}^{+}\right)$in a similar arcjet experiment where PICA was tested. ${ }^{12}$ However other species have emission lines at these same wavelengths such as iron $(\mathrm{Fe})$ at 393.0, hydrogen $(\mathrm{H})$ at 397.0. A weak emission line also appears near $656.3 \mathrm{~nm}$, where the strongest $\mathrm{H}$ line is expected. However, many of the other expected strong $\mathrm{H}$ lines are not present, which suggests that the $397 \mathrm{~nm}$ line is not $\mathrm{H}$. Fe has numerous lines in this spectral region including a $527.0 \mathrm{~nm}$ line which may be responsible for the observed emission at $526.7 \mathrm{~nm}$. But again, many strong Fe lines are not present in the spectrum which suggests that $\mathrm{Fe}$ is not present in abundance. In summary, many spectral lines are observed but few could be conclusively identified.

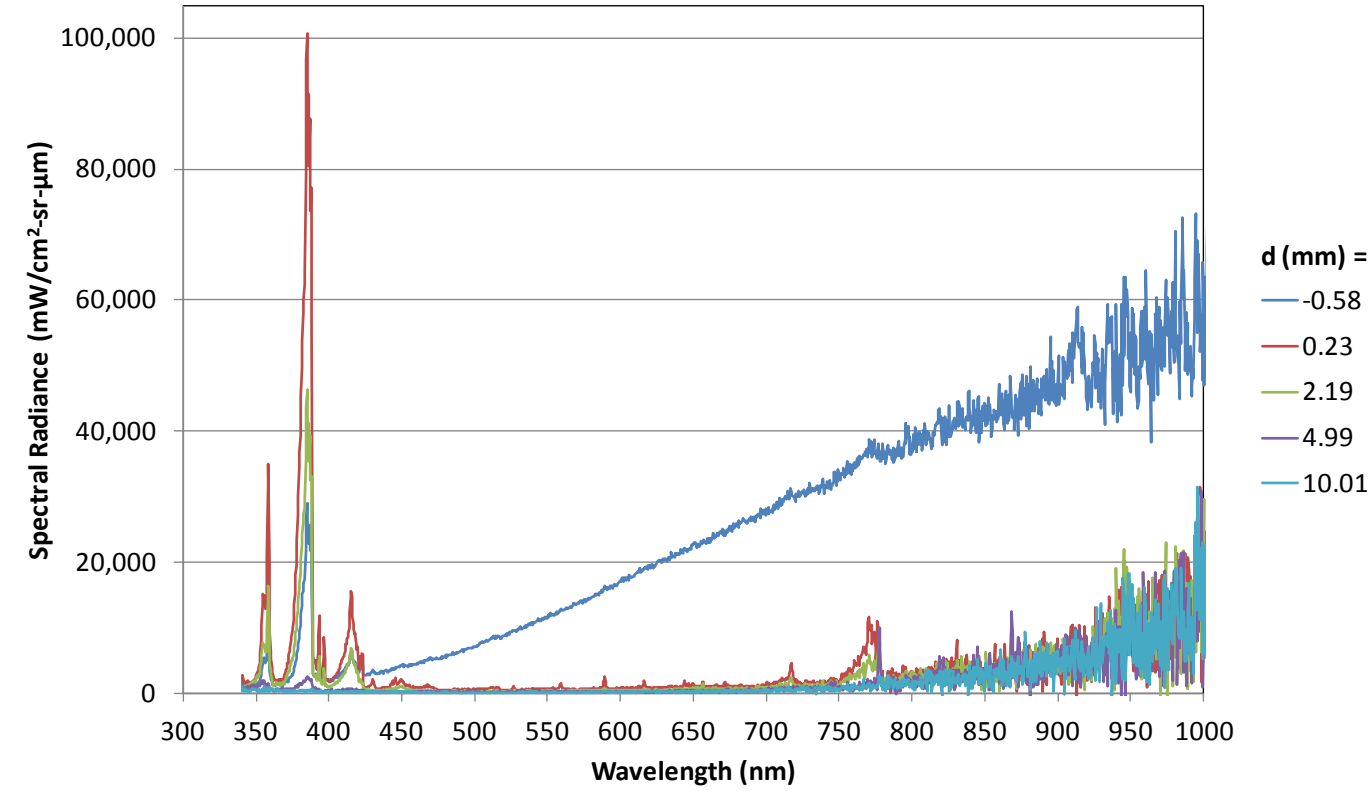

Figure 14. Emission spectra obtained with Air flow over the PICA material in Run 6 showing measurements at different spatial locations in front of the material. These spectra were obtained during the first stepper-motor scan of Run 6 (first 6 seconds of the run).

\section{Spatial distribution of species}

Because of the short sample-insertion duration (30 s) of PICA tests, averaged measurements obtained at different spatial locations, like those shown in Figs. 10-12 could not be obtained. Instead, the stepper motor used to translate the fiber horizontally was continuously scanned back and forth to vary $d$. The motor scanned $\sim 15 \mathrm{~mm}$ in $\sim 6$ seconds, stopped, and then scanned back at the same speed. This was repeated for the duration of the run, yielding 5 spatial scans. However only the first three spatial scans could be used because the sample receded so far by the fourth scan that the surface of the sample could not be located and therefore it was not possible to determine the spatial location of the data obtained for the final scans. The advantage of this scanning approach is that a) many spatial locations could be probed during a run, b) the location of the measurement could be determined from the scan allowing the recession of the sample to be taken into account in post-processing and c) the time evolution of the ablation process could be studied since the same sample was tested at different times during a run.

Figure 14 shows some of the spectra obtained during the first scan, which started by viewing the side of the sample and then passed into the flow, still using the configuration shown in Figs. 1 and 2. When the sample is at negative values of $d$, significant blackbody radiation is seen. Once the measurement volume is away from the 
surface $(d>0)$, spectra similar to Fig. 13 are observed, though the intensity varies with location. As shown in Fig. 14 , by the time the probe volume is $5 \mathrm{~mm}$ from the surface (purple curve) emission from CN (e.g. at 359.0, 388.3, and $421.6 \mathrm{~nm}$ ) has vanished but emission from $\mathrm{O}$-atoms at $777.2 \mathrm{~nm}$ and $\mathrm{N}$-atoms at $868.3 \mathrm{~nm}$ are still observed. This can be seen more clearly in Fig. 15, in which the vertical axis is the wavelength and the horizontal axis is the distance of the probe volume from the surface, $d$. The $777.2 \mathrm{~nm}$ O-atom line is seen to exist all the way to $d=12 \mathrm{~mm}$ while the other spectral features, such as $\mathrm{CN}$ only penetrate $3-5 \mathrm{~mm}$ away from the surface. Figure 16 shows spatial profiles of selected spectral lines. The $\mathrm{O}-$ and $\mathrm{N}$-atom lines both increase in intensity as $d$ increases away from the surface, then fall as $d$ further increases, giving an indication of the bow shock standoff distance $(7.5 \pm 1 \mathrm{~mm})$. The other properties appear to drop off nearly exponentially with distance from the surface, some faster than others. These profiles could provide validation data for codes developed to predict ablation.

Note that, for each selected spectral line, Fig. 16 shows data from the three different spatial scans obtained during a single run, with consecutive points from each scan connected by lines. For $\mathrm{CN}$ and $\mathrm{Ca}^{+}$the first scan (not labeled) shows a higher intensity by about $15 \%$. The two subsequent scans produce similar, smaller amplitudes. The same is observed in Fig. 15, in which all three scans are seen to be relatively similar with slightly higher emission in the first scan, Fig. 15(a). A noticeable difference in Fig. 15 is that the sample surface itself $(d<0)$ is increasing in radiance as the sample heats up during the run.

\section{Discussion}

The apparatus could be improved in a few ways. We suspect that much of the emission above $800 \mathrm{~nm}$ in many of the figures (for example Fig. 15) is thermal radiation from the test sample scattering off the walls of the facility and into the fiber. To prevent collection of this scattered light, the collection fiber's view past the sample should be directed out of the facility through a window on the far side of the facility. In fact, a periscope will be required near the exit window in HYMETS since the windows are not aligned with the front of the sample (see Fig. 2).

The calibration of the spectrometer should be extended into the UV spectral region by using a calibrated deuterium lamp. Another improvement might be to use an imaging

(a)

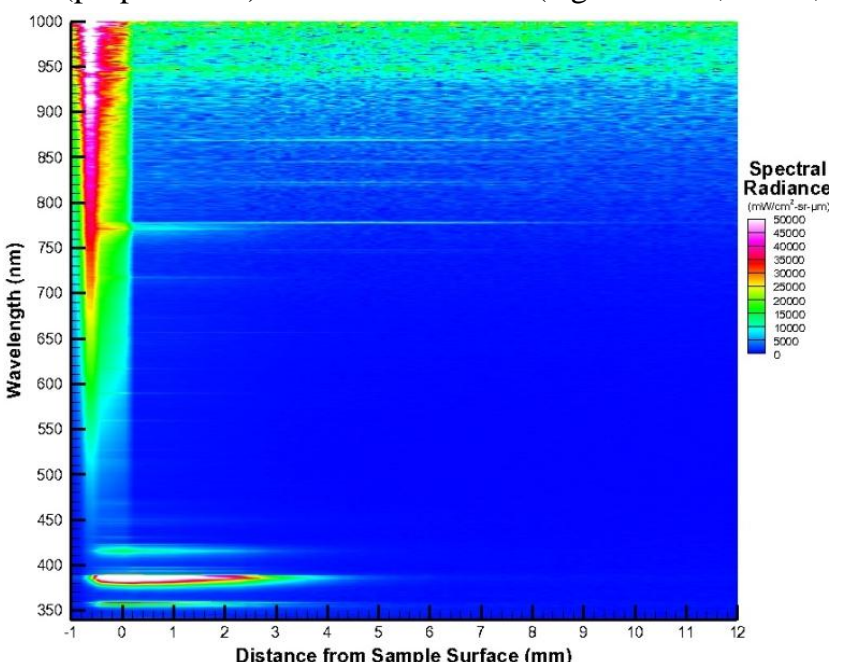

(b)
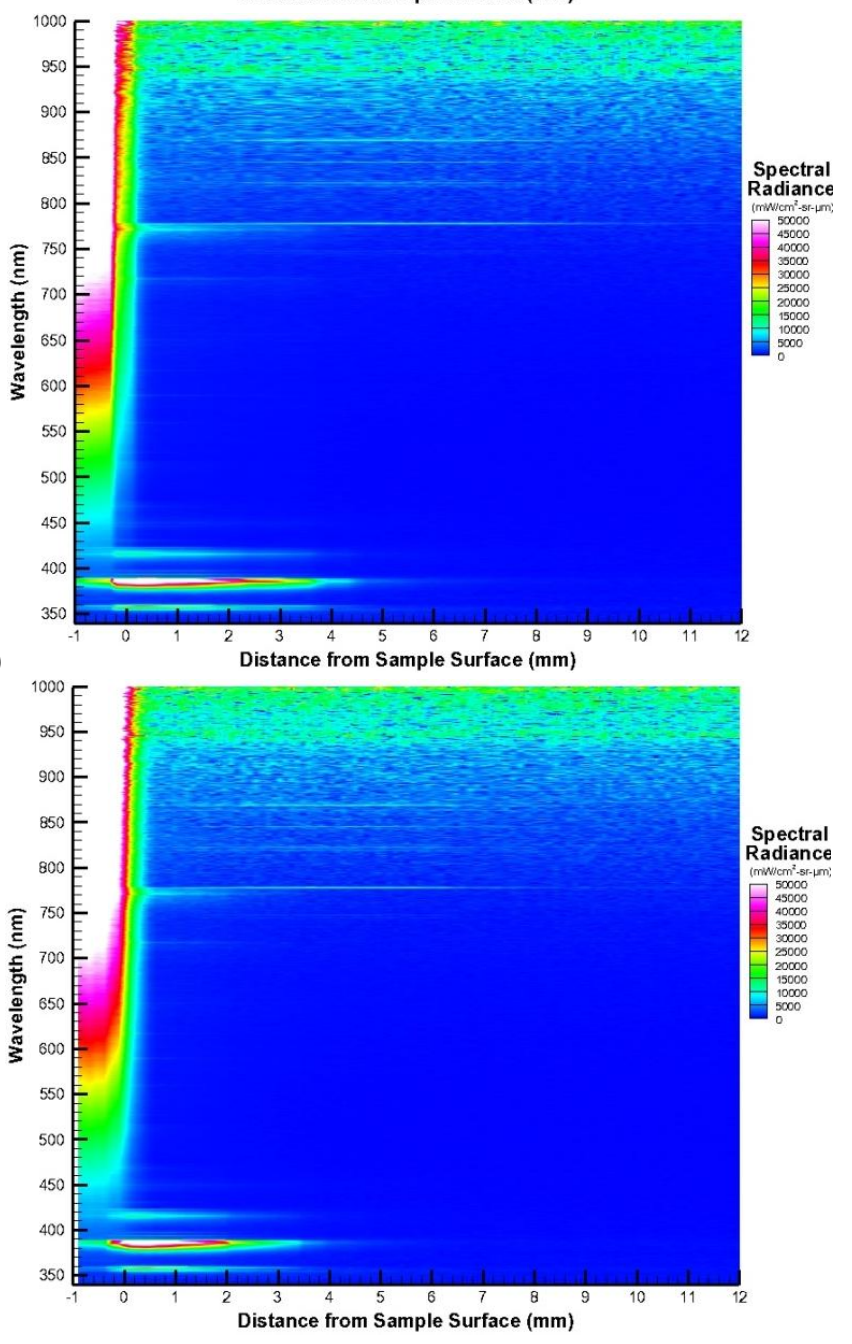

Figure 15 Spectral radiance measured while testing PICA samples in Air. The first scan (a) occurred during the first 6 seconds of the run and was obtained left-to-right, the second scan (b) between 6 and 12 seconds, right-to-left and the third (c) between 12 and $18 \mathrm{~s}$, left-to-right.

19 
spectrometer with the slit oriented perpendicular to the sample to obtain spatial profiles instantaneously or parallel to the sample to acquire data for Abel inversion. However, this imaging equipment is more costly and time consuming to set up. A limitation of $2 \mathrm{D}$ imaging spectrographs is that they acquire data at an order of magnitude lower repetition rate compared to the spectrometer used in the current experiment, which could be useful for studying time-varying phenomena. Even with the existing instrument, additional measurements can be obtained and transformed using Abel inversion, to obtain spatial flowfield information. Still, without Abel inversion, these measurements can be compared directly to computational codes that compute the emission along the line of sight of the measurement volume.

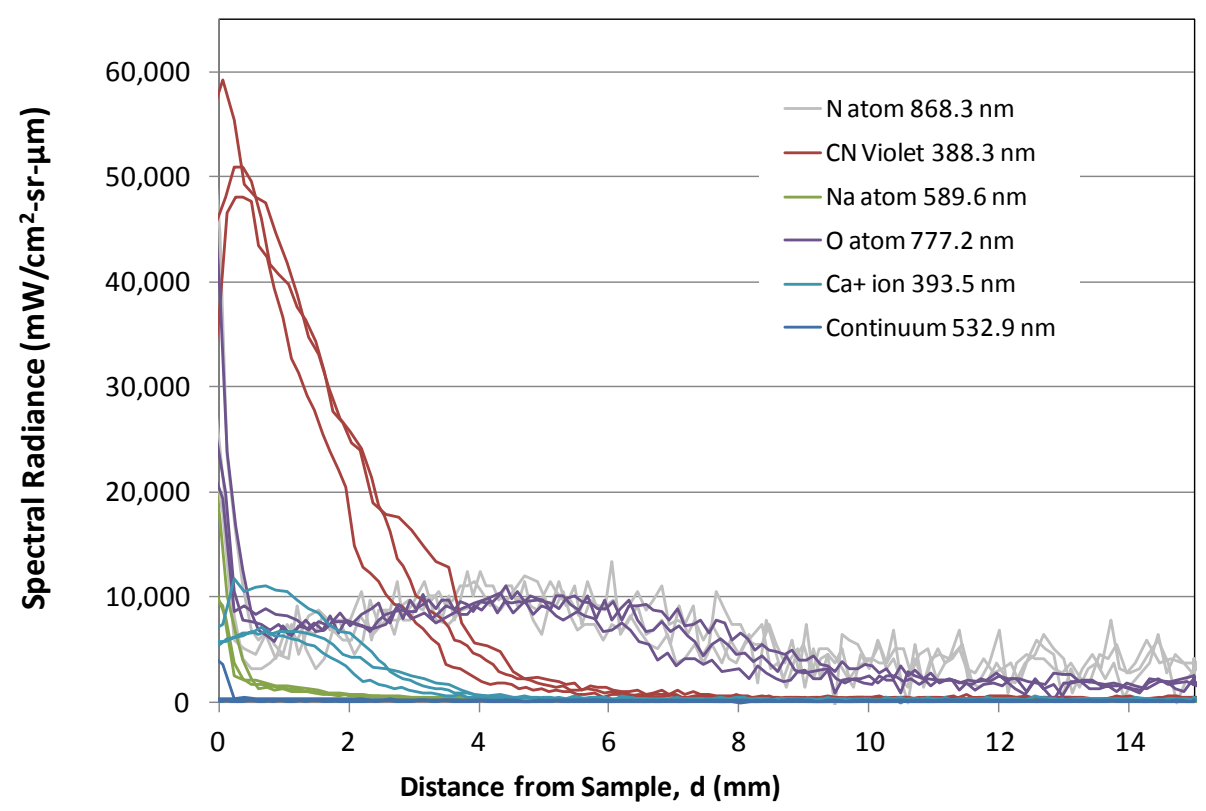

Figure 16. Spatial variation of selected emission lines obtained in Run 6 with Air -simulant test gas and a PICA test sample.

\section{Conclusions}

An emission spectroscopy system was set up, calibrated and used to measure the absolute spectral radiance in an arc-jet materials testing facility. Three different test gases were used: Air, mostly- $\mathrm{N}_{2}$, and Mars simulant mixtures. Two different materials were tested: SiC disks and PICA samples, both tested in end-on cylinder configurations.

For each condition many of the atomic and molecular species contributing to the spectra were identified. Testing the PICA sample resulted in an emission spectrum that looked qualitatively similar to the Mars simulant when SiC was the sample. The similarities were mainly that $\mathrm{CN}$ emission dominated the spectrum and that $\mathrm{O}$ - and $\mathrm{N}$-atom lines were observed, though differences were also noted. For example, the $\mathrm{C}_{2}$ Swan bands were absent while testing the PICA sample. Both Air and $\mathrm{N}_{2}$-simulant spectra were dominated by the emission from $\mathrm{N}_{2}$ and its ions. Another major result of the study is that the Mars simulant test gas produced about an order of magnitude more radiation than Air, which in turn produced about a factor of two more radiation than $\mathrm{N}_{2}$ at approximately the same enthalpy.

Shock standoff distances were determined during the tests. As expected because of the blowing effect of an ablator, the PICA material produced a significantly larger shock standoff distance than SiC, though they were tested at different enthalpy condition. During testing of PICA, two classes of species were identified: those that are present in the post-shock region, such as $\mathrm{O}$ - and $\mathrm{N}$-atoms and those that are only present within a few $\mathrm{mm}$ of the sample surface, such as $\mathrm{CN}$. considered characteristic for the material response.

Using repeated runs, the repeatability of the measured spectral radiance was determined to be a factor of 2 in the worst case, when tests were performed on separate days. Even tests performed on the same day, during the same facility run showed variation on the order of $25 \%$. The variation of the emission within a single run was studied and was observed to vary by $15 \%$ during a single data acquisition lasting just 30 seconds. These variations appear to originate in the flow and not because of an error in the instrumentation; however, further research is required to understand this time variation in more detail. 


\section{Acknowledgments}

This work was funded in part by NASA's Fundamental Aeronautics Program, Hypersonics Project, Materials and Structures (M\&S) Discipline. We would like to acknowledge the assistance of Jennifer Inman of NASA Langley and Simone Eichmann of the Lehrstuhl für Technische Thermodynamik (LTT) at the University of Erlangen in Erlangen, Germany for assistance in preparing the manuscript. We wish to acknowledge Jay Grinstead, Brett Cruden and Michael Winter who work at NASA Ames Research Center for providing advice, loaning equipment and making suggestions for improving this manuscript.

\section{References}

${ }^{1}$ Splinter, Scott C., Bey, Kim S., Gragg, Jeffrey G., and Brewer, Amy R., "Comparative Measurements of Earth and Martian Entry Environments in the NASA Langley HYMETS Facility," the 49th AIAA Aerospace Sciences Meeting, Paper AIAA-2011-1014, Orlando Florida, January 2011.

${ }^{2}$ J. A. Inman, B. F. Bathel, C. T. Johansen, P. M. Danehy, S. B. Jones, J. G. Gragg, and S. C. Splinter, "Nitric Oxide PLIF Measurements in the Hypersonic Materials Environmental Test System (HYMETS)", the 49th AIAA Aerospace Sciences Meeting, Paper AIAA-2011-1090, Orlando Florida, January 2011.

${ }^{3}$ Zhang, Feng-Yuan, Komurasaki, Kimiya, Iida, Teruhito, and Fujiwara, Toshi, "Diagnostics of an Argon Arcjet Plume with a Diode Laser," Applied Optics, Vol. 38, No. 9, 20 March 1999, pp. 1814-1822.

${ }^{4}$ Grinstead, Jay H., Driver, David M., and Raiche, George A., "Radial Profiles of Arcjet Flow Porperties Measured with Laser-Induced Fluorescence of Atomic Nitrogen," $41^{\text {st }}$ Aerospace Sciences Metting and Exhibit, Reno, NV, AIAA Paper 2003-0400, 6-9 January 2003.

${ }^{5}$ Grinstead, Jay H., Harris, Christopher L., Yeung, Dickson, Scott, Gregg P., Porter, Barry J., Graube, Peter, and Greenberg, Reid B., "Next-Generation Laser-Induced Fluorescence Diagnostic Systems for NASA Arc Jet Facilities," 47 $7^{\text {th }}$ AIAA Aerospace Sciences Meeting Including The New Horizons Forum and Aerospace Exposition, Orlando, FL, AIAA Paper 2009-1521, 5-8 January 2009.

${ }^{6}$ Takayanagi, Hiroki, Mizuno, Masahito, Fujii, Keisuke, Suzuki, Toshiyuki, and Fujita, Kazuhisa, "Arc Heated Wind Tunnel Flow Diagnostics using Laser-Induced Fluorescence of Atomic Species," $47^{\text {th }}$ AIAA Aerospace Sciences Meeting Including The New Horizons Forum and Aerospace Exposition, Orlando, FL, AIAA Paper 20091449, 5-8 January 2009.

${ }^{7}$ Del Vecchio, Antonio, Palumbo, Giuseppe, Koch, Uwe, and Gulhan, Ali, "Temperature Measurements by Laser-Induced Fluorescence Spectroscopy in Nonequilibrium High-Enthalpy Flow," Journal of Thermophysics and Heat Transfer, Vol. 14, No. 2, April-June 2000, pp. 216-224.

${ }^{8}$ Mizuno, Masahito, Ito, Takeshi, Ishida, Kiyomichi, and Nagai, Junsei, "Laser Induced Fluorescence of Nitric Oxide and Atomic Oxygen in an Arc Heated Wind Tunnel," $39^{\text {th }}$ AIAA Thermophysics Conference, Miami, FL, AIAA Paper 2007-4405, 25-28 June 2007.

${ }^{9}$ Scott, Carl D., "Survey of Measurements of Flow Properties in Arcjets," Journal of Thermophysics and Heat Transfer, Vol. 7, No. 1, Jan.-March 1993, pp. 9-24.

${ }^{10}$ Arepalli, Sivaram, Yuen, Eric H., and Scott, Carl D., "Application of Laser Induced Fluorescence for Flow Diagnostics in Arc Jets," AIAA/ASME $5^{\text {th }}$ Joint Thermophysics and Heat Transfer Conference, Seattle, WA, AIAA Paper 90-1763, 18-20 June 1990.

${ }^{11}$ J. Luque, W. Juchmann, E. A. Brinkman, and J. B. Jeffries, "Excited state density distributions of H, C, C2, and $\mathrm{CH}$ by spatially resolved optical emission in a diamond depositing dc-arcjet reactor" J. Vac. Sci. Technol. A 16 (2), Mar/Apr 1998, p. 397-408.

${ }^{12}$ T. Schott, G. C. Herring, M. M. Munk, J. H. Grinstead, D. K. Prabhu, "Fiber-Based Measurement of BowShock Spectra for Reentry Flight Testing" 48th AIAA Aerospace Sciences Meeting Including the New Horizons Forum and Aerospace Exposition, 4 - 7 January 2010, Orlando, Florida, AIAA 2010-301.

${ }^{13}$ A. Cipullo, F. De Filippis, L. Zeni, "Temperature Measurements of Air Plasma Flow Using Optical Emission Spectroscopy," J. of Thermoph. and Heat Transf. Vol. 25, No. 3, Jul.-Sep. 2011.

${ }^{14}$ Abel inversion reference.

15 C. O. Johnston, A. Mazaheri, P. Gnoffo, B. Kleb, K. Sutton, D. Prabhu, A. M. Brandisk, D. Bose, "Assessment of Radiative Heating Uncertainty for Hyperbolic Earth Entry", Paper AIAA 2011-3145 at the 42nd AIAA Thermophysics Conference, Honolulu, Hawaii, 27 - 30 June 2011.

${ }^{16}$ A. R. Brewer S. Splinter J. Gragg, "Determination of Uncertainties in the LaRC HYMETS Facility," NASA $\mathrm{CR}$ (in preparation). 
17 Ralchenko, Yu., Kramida, A., Reader, J. and NIST ASD Team (2011). NIST Atomic Spectra Database (version 4.1), [Online]. Available: http://physics.nist.gov/asd [Monday, 28-Nov-2011 19:53:23 EST]. National Institute of Standards and Technology, Gaithersburg, MD.

${ }^{18}$ R. W. B. Pearse and A. G. Gaydon, "The Identification of Molecular Spectra," $4^{\text {th }}$ ed., John Wiley and Sons, New York, 1976.

${ }^{19}$ M. Playez, "Titan atmosphere plasma characterization using spectroscopic measurement techniques," PhD Dissertation, Ecole-Central Paris and Von Karman Institute for Fluid Dynamics, 2006.

${ }^{20}$ C. S. Park, D. G. Fletcher and J. M. Donohue, "Spatially resolved shock layer emission measurements and analysis in an arc-jet facility" AIAA Conference Paper 99-1046, 1999.

${ }^{21}$ W.L. Wiese, J.R. Fuhr, and T.M. Deters, “Atomic transition probabilities of carbon, nitrogen, and oxygen : a critical data compilation," J. Phys. Chem. Ref. Data, Monograph 7, Published by the American Chemical Society and the American Institute of Physics for the National Institute of Standards and Technology (NIST), 1996.

${ }^{22}$ E. Kamaratos, " $\mathrm{N}_{2}\left(C^{3} \Pi_{\mathrm{u}}\right)-\mathrm{N}_{2}\left(\mathrm{~B}^{3} \Pi_{\mathrm{g}}\right)+\mathrm{h} v$ fluorescence increase due to collisional intermolecular energy transfer induced by discharged $\mathrm{O} 2$ in active nitrogen and oxygen mixtures," Journal of Quantitative Spectroscopy \& Radiative Transfer v.110 p. 264-283, 2009

23 B. Cruden, R. Martinez, J. Grinstead, J. Olejniczak, "Simultaneous Vacuum-Ultraviolet Through Near-IR Absolute Radiation Measurement with Spatiotemporal Resolution in An Electric Arc Shock Tube," AIAA-20094240, 41st AIAA Thermophysics Conference, San Antonio, Texas, June 22-25, 2009.

${ }^{24}$ M. Winter, and G. Herdrich, "Heat Shield Temperatures and Plasma Radiation obtained from Spectroscopic Observation of the STARDUST Re-Entry in the Near UV," AIAA 2008-121246th AIAA Aerospace Sciences Meeting and Exhibit, Reno, Nevada, January 7-10 2008. 